"This accepted author manuscript is copyrighted and published by Elsevier. It is posted here by agreement between Elsevier and MTA. The definitive version of the text was subsequently published in [PROGRESS IN BIOPHYSICS AND MOLECULAR BIOLOGY 114(3):153169 (2014) DOI:10.1016/j.pbiomolbio.2014.03.001]. Available under license CC-BY-NCND." 


\title{
Review
}

\section{Asymmetric perturbations of signalling oligomers}

\author{
Gábor Maksay $^{1 *}$ and Orsolya Töke $e^{1,2}$ \\ ${ }^{1}$ Research Centre for Natural Sciences, Hungarian Academy of Sciences, ${ }^{2}$ Institute of Organic
} Chemistry, P.O. Box 17, H-1525 Budapest, Hungary

\begin{abstract}
This review focuses on rapid and reversible noncovalent interactions for symmetric oligomers of signalling proteins. Symmetry mismatch, transient symmetry breaking and asymmetric perturbations via chemical (ligand binding) and physical (electric or mechanic) effects can initiate the signalling events. Advanced biophysical methods can reveal not only structural symmetries of stable membrane-bound signalling proteins but also asymmetric functional transition states. Relevant techniques amenable to distinguish between symmetric and asymmetric architectures are discussed including those with the capability of capturing low-populated transient conformational states. Typical examples of signalling proteins are overviewed for symmetry breaking in dimers (GPCRs, growth factor receptors, transcription factors); trimers (acid-sensing ion channels); tetramers (voltage-gated cation channels, ionotropic glutamate receptor, CNG and CHN channels); pentameric ligand-gated and mechanosensitive channels; higher order oligomers (gap junction channel, chaperonins, proteasome, virus capsid); as well as primary and secondary transporters. In conclusion, asymmetric perturbations seem to play important functional roles in a broad range of communicating networks.
\end{abstract}

\footnotetext{
Abbreviations: AA, alternating access; ABC, ATP-binding cassette; ASIC, acid-sensing ion channel; $\beta_{2} \mathrm{AR}, \beta_{2}$-adrenergic receptor; BRET, bioluminescence resonance energy transfer; CAP, catabolite activator protein; CNG, cyclic nucleotide-gated; cryo-EC, cryo-electron crystallography; EC, extracellular; EM, electron microscopy; EGFR, epidermal growth factor receptor; EPR, electron paramagnetic resonance; FRET, fluorescence resonance energy transfer; FS, fluorescence spectroscopy; $\mathrm{GABA}_{\mathrm{A}} \mathrm{R}$, A-type $\gamma$-aminobutyric acid receptor; GPCR, G protein-coupled receptor; IC, intracellular; iGluR, ionotropic glutamate receptor; MD, molecular dynamics; MS, mass spectroscopy; NB, nucleotide binding; NGF, nerve growth factor, NMR, nuclear magnetic resonance; pLGIC, pentameric ligand-gated ion channel; SANS, small-angle neutron scattering; SAXS, small-angle $\mathrm{X}$-ray scattering; TM, transmembrane; XRC, X-ray crystallography.
}

*Tel.: +361 382-6658, fax: +361. E-mail address: maksay.gabor@ttk.mta.hu 
Keywords:

symmetric protein oligomers; asymmetric activation, membrane receptors; ion channels; transporters; biophysical structural techniques; symmetry-asymmetry distinction

\section{Contents}

1. Introduction

2. Methods to reveal structural symmetry and asymmetry of oligomeric proteins

2a. X-ray crystallography

2b. Fluorescence spectroscopy

2c. Electron microscopy

2d. Nuclear magnetic resonance spectroscopy

2e. Electron paramagnetic resonance spectroscopy

2f. Small angle X-ray and neutron scatterings

2g. Mass spectroscopy

2h. Methodical comparison of biophysical techniques

3. Structural symmetry and transient asymmetry of signalling proteins

3a. Dimeric GPCRs, growth factor receptors and transcription factors

3b.Trimeric acid-sensing ion channel and tetrameric voltage-gated cation channels, ionotropic glutamate receptors, viral proton channels, $\mathrm{CNG}$ and $\mathrm{CHN}$ channels

3c. Pentameric ligand-gated and mechanosensitive channels

3d. Higher order oligomers: gap junction channel, chaperonins, proteasome and virus capsid

3e. Primary and secondary transporters

4. Conclusions 


\section{Introduction}

What is so special in symmetry? Human perception of symmetric objects and structures has subjective and holistic characteristics. Symmetry can be associated with harmony, pleasure, stability (Blundell and Srinivasan, 1996; Goodsell and Olson, 2000; Kojić-Prodić and Štefanić, 2010; Thompson, 1952). In contrast, symmetry violation and asymmetry might seem disharmonic, transient and instable. It reflects some kind of motion or change: (bio)chemical reactions, transition states, function, metamorphosis, development, even revolution. These associations might seem trivial, but they are far from evident, especially if the motions and changes are very short, slight and invisible. The contrast between symmetry and asymmetry is present throughout the Universe, from Big Bang down to particle physics (e.g. Higgs boson). How is this contrast manifested in life sciences?

The maintenance of living organisms and adaptation to environmental challenges involve signalling processes. Chemical communication, the interaction of chemical signals with signalling proteins elicit physiological responses. Recent biophysical methods have revealed that these physiological processes involve several weak, rapid, reversible, non-covalent interactions. The structural secret of life is thus wrapped in a versatile network of physico-chemical interactions (Gong et al., 2009; Zhou and Gilson, 2009). This review is focused on non-covalent interactions of signalling proteins with a few coupled covalent biochemical changes.

Most signalling proteins have oligomeric quaternary structures. These proteins have presumably evolved via gene duplication, repetition and fusion of ancient peptide modules into homooligomers (Broom et al., 2012; Dayhoff et al., 2010; Kurian and Eisenberg, 2007). This is obviously a source of emerging structural symmetry (André et al., 2008; Lee and Blaber, 2011; Schulz, 2009). Some of the benefits of symmetric oligomers are greater biosynthetic and folding 
efficiency; amenability to cooperativity, allosteric regulation and adaptation; stability and reduced aggregation (André et al., 2008; Broom et al., 2012; Goodsell and Olson, 2000).

How do oligomeric proteins function concerning symmetry? Monod, Wyman and Changeux (Monod et al., 1965) introduced a concerted, symmetric model of allostery to interpret regulatory mechanisms of oligomeric enzymes. According to the MWC model, ligand-free homooligomers exist in equilibrium of different states; oligomeric structures are symmetric; protomer conformations change in a concerted way; ligand binding maintains the symmetric arrangement of protomers whereas it shifts the equilibrium of pre-existing oligomeric conformations. The MWC model was extended to the acetylcholine receptor and other signalling proteins (Changeux et al., 1984; Karlin, 1967). In contrast to the MWC model, Koshland, Némethy and Filmer (Koshland et al., 1966) introduced a sequential model. According to the KNF model, conformational changes of protomers are consecutive and asymmetric. Ligands bind sequentially with increasing affinity when the structure of a ligand and its binding site are accommodated to each other via induced fit. It should be noted that symmetry maintenance was a contradicting issue in the MWC and KNF models. The demonstration of rapid dynamics of conformational ensembles of proteins has then led to the reconciliation of MWC and KNF models. According to the recent dynamic model, ligands select from pre-existing conformational states of proteins and binding to the most suitable one shifts the equilibrium (Boehr et al., 2009; Smock and Gierasch, 2009; Tsai et al., 1999). However, the side chains of individual protomers are accommodated to ligand binding (KNF model). Thus, both conformational selection and induced fit play important roles in molecular recognition. These principles can gradually gain application not only in biotechnology but also in the pharmacological fine-tuning of signalling (Maksay, 2011).

Structural symmetry is also important in protein dynamics (Matsunaga et al., 2012; Swapna et al., 2012). Global symmetry is often associated with local binding asymmetry (Goodsell and Olson, 2000). Some specific requirements of signalling oligomers such as rapid and reversible 
action cannot be reconciled with high stability. They need dynamic flexibility; a trade-off between stability and evolvability; interface mutations for diversification and signalling selectivity (Tokuriki and Tawfik, 2009). Some symmetric signalling oligomers have been recently shown to function via asymmetric perturbation, transiently breaking symmetry (Mowrey et al., 2013; Maksay, 2013). Asymmetric transition states can be hopefully exploited in structure-based drug design (Brown, 2006; Lee and Craik, 2009).

The term symmetry will be primarily used here in a structural sense. However, there is a universal definition: symmetry means invariance to transformations. This maintenance of properties is similar to thermodynamic stability. Indeed, the oligomeric symmetries of signalling proteins contribute to structural stability.

The structural asymmetries discussed here should be distinguished from the functional and operational asymmetries of proteins. Functional asymmetry can be observed when identical domains perform distinct tasks: i) the zinc fingers of the Egr-1 transcription factor perform rapid scanning and stable recognition (Zandarashvili et al., 2012) and ii) histidine kinase receptor dimers possess either kinase or phosphatase activities (Moore and Hendrickson, 2012). Operational asymmetry arises when the symmetry of enzyme reaction cycles is broken, which can lead to evolutionary consequences (García-Bellido, 1996).

In the first part of the review we summarize some of the advanced biophysical methodologies which can be instrumental in revealing transient structural asymmetry in oligomeric proteins. In the second part, the structural (a)symmetry of signalling proteins will be overviewed according to the oligomerization state, structural family and function. 


\section{Methods to reveal structural symmetry and asymmetry of oligomeric proteins}

\section{2a. X-ray crystallography}

X-ray crystallography (XRC) has become the major method for high-resolution structure elucidation of proteins. Due to the obstacles of crystallization, the XRC structures of just the extracellular (EC) ligand-binding or intracellular (IC) functional coupling domains have been determined at first for several membrane-bound signalling proteins (Alvarado et al., 2010; Kunishima et al., 2000). To overcome the difficulties posed by the relatively small polar surface of membrane proteins, shorter-chain detergents in combination with amphiphile additives, less hydrophobic point mutations, protein fusion, complexation with an antibody fragment or with a crystallization 'chaperone' have been introduced into conventional mixed micelle crystallization techniques (Caffrey et al., 2012). Additional difficulties, such as conformational heterogeneity and inherent protein flexibility can be reduced by inhibitors or antibodies rigidifying the structure of the target protein. These methodological advances have contributed to the crystallization of a broad range of membrane-bound signalling proteins (Rasmussen et al., 2011a; Uysal et al., 2009; Krishnamurthy and Gouaux, 2012).

Alternative strategies for the crystallization of membrane proteins involve the formation of an extended bilayer of lipid, detergent, and target protein (Caffrey et al., 2012). Among these techniques, the lipidic mesophase and specifically the cubic phase method has been used successfully for GPCRs. The main advantage of the technique is that crystallization takes places within a soft lipid bilayer, which helps maintaining functionally relevant states such as observed for G-protein- and agonist-bound $\beta_{2}$-adrenergic receptors $\left(\beta_{2} \mathrm{AR}\right)$ (Rasmussen et al., 2011b).

While a crystal structure is likely the lowest energy state in the crystal lattice, it is not necessarily the lowest energy state in solution. Also, crystallization is often accompanied by symmetric contacts existing only in the crystal. Thus it is important to distinguish between 
crystallographic and non-crystallographic symmetries, that is, artefacts and functionally relevant structures, as well as to cross-validate the interpretation of structural results (Fabiola et al., 2006). X-ray free-electron lasers and serial femtosecond crystallography offer a great promise for roomtemperature high-resolution data for crystals of sub-micrometer size and appears to be a more accurate representation of the native structure for membrane receptors (Liu et al., 2013).

In conclusion, large and asymmetric macromolecular assemblies are challenging and require special strategies for the measurement of diffraction intensities and phase determination (Mueller et al., 2007). XRC studies should ideally be combined with complementary techniques in solution such as cryo electron microscopy and small-angle scattering (Abrahams and Ban, 2003).

\section{2b. Fluorescence spectroscopy}

The sensitivity of the spectroscopic characteristics of fluorophores to the physico-chemical properties of their molecular environment makes fluorescence spectroscopy a powerful biophysical tool for the study of the thermodynamics and kinetics of receptor-ligand interactions and ligandinduced conformational changes leading to signal transduction (Hovius et al., 2000; Lohse et al., 2008; Böhme and Beck-Sickinger, 2009).

The advantages of fluorescence-based techniques include low sample concentrations $(\sim \mathrm{nM}-$ $\mu \mathrm{M}$ ) and near physiological experimental conditions (i.e. membrane proteins reconstituted in lipid bilayers, living cells). Fluorescent markers can be introduced into ligands and proteins by covalent modifications of specific functional groups (thiols, amines) engineered by site-directed mutagenesis allowing selective, single-site labelling. Recombinant protein expression techniques using auxotroph E. coli (Ross et al., 1992) and suppressor tRNA technology can be used for site-specific introduction of unnatural fluorescent amino acids (Mendel et al., 1995) allowing selective monitoring of conformational changes in homodimers (Damian et al., 2006). Semisynthetic techniques allowing the engineering of proteins with chemically defined site-specific modification 
have also been increasingly used (Focke and Valiyaveetil, 2010). Finally, the green fluorescent protein and its mutated derivatives can be used to monitor and localize gene expression, proteins, and molecular interactions in living cells (Tsien et al., 1998).

By monitoring the fluorescence of the ligand or that of the target protein, fluorescence spectroscopy is well suited to reveal phenomena such as binding cooperativity (Alvarado, 2010) and by the application of special labelling techniques, distinguish between cis and trans activation in GPCR dimers (Damian et al., 2006, 2008). Site-directed fluorescence spectroscopy can also be used to identify different structural domains associated with asymmetric ligand binding (Sommer et al., 2012). Additionally, quenching experiments can be exploited in the study of membrane channels and transporters to monitor gating (Birkner, 2012) and characterize translocation pathways (Smriti et al., 2009) and conformational heterogeneity (Siarheyeva, 2010) in general.

The interaction of two different fluorophores via a distance-dependent dipole-dipole mechanism in a Förster (fluorescence) resonance energy transfer (FRET) experiment can be exploited in structural studies. Due to its capability of measuring long distances (up to $\sim 80 \AA$ ) FRET is particularly suitable to distinguish between different subunit orientations of oligomeric proteins and can serve as evidence for asymmetric intersubunit rearrangement accompanying activation (Matsushita et al., 2010). Along with FRET, fluctuations in fluorescence intensity induced by a particular molecular process can be exploited in mechanistic studies of signalling molecules as shown recently in a fluorescence cross-correlation spectroscopy (FCCS) study of EGFR (Endres et al., 2013).

Yet another advantage of fluorescence spectroscopy is that bulk measurements can be complemented with single-molecule analysis (Joo et al., 2013). An elegant example of this is a study of the homodimeric multidrug efflux protein EmrE, where bulk and single-molecule FRET measurements were used as additional evidence for an asymmetric antiparallel arrangement of the two subunits (Morrison et al., 2012). Single-molecule FRET in general has proven to be a highly 
valuable biophysical tool for distinguishing between asymmetric and symmetric protein complexes (Takei et al., 2012) and revealing directionality in macromolecular interactions (Cristóvao et al., 2012). Additional single-molecule optical techniques such as fluorescent-molecule video imaging have been used in recent years with great success to obtain a dynamic insight into receptor oligomerization and mobility on the surface of intact cells (Kasai and Kusumi, 2014).

While in steady-state experiments the signals of all fluorophore populations are averaged, time-resolved fluorescence spectroscopy provides additional information on the lifetime of the excited states of fluorophores allowing independent observation of their different populations (e.g. free $v s$. receptor-bound ligands). For instance, with labelled antibodies raised against each subunit (Goudet et al., 2005; Hlavackova et al., 2005) or with selective fluorescent ligands (Albizu et al., 2010), time-resolved FRET could be employed to demonstrate the asymmetric activation of various GPCR dimers at the surface of living cells and correlate local structural changes with functional states of ion channels (Kusch et al., 2012).

Along with fluorescence, luminescence-based techniques allow structural and kinetic characterization of protein-ligand and protein-protein interactions in signalling processes. In an illustrative example, bioluminescence resonance energy transfer (BRET) and electrophysiology have been used to characterize the complex of melatonin MT1 receptor, RGS20, and $\mathrm{G}_{\mathrm{i}}$ proteins in its basal and agonist-activated state to reveal functional asymmetry of RGS20 and $\mathrm{G}_{\mathrm{i}}$ coupling to MT1 (Maurice, 2010).

\section{2c. Electron microscopy}

For larger and complicated molecular assembly, flexible components, small amount of sample, less purity, that is, when crystallization fails, especially for membrane proteins, chaperones and viruses, electron microscopy (EM) is the optimal method of choice (Rossmann et al., 2005). The most powerful approach to reduce the detrimental effect of electrons on chemical bonds in EM 
is to perform the imaging experiment at cryogenic temperatures (Saibil 2000). Among the general approaches in cryo-EM for addressing biological systems of different levels of complexity (Milne et al., 2013), single-particle analysis (Zhou, 2008) is a commonly used strategy for structure elucidation of membrane protein complexes at subnanometer resolution (Ludtke et al., 2011; Lau and Rubinstein, 2012). Another powerful approach with the capability of providing atomic resolution structural information on membrane proteins is cryo-electron crystallography (cryo-EC) (Ubarretxena-Belandia and Stokes, 2012). The main advantage of the method is that 2D crystals of proteins are formed in a lipid bilayer, where the surrounding lipids allow conformational changes upon binding interactions without destroying the crystal lattice. Thus, unlike in $\mathrm{XRC}$, where proteins need to be complexed with their binding partners before crystallization, cryo-EC provides a way to compare structures before and after adding a ligand to pre-existing crystals (Unwin, 1995). We note that by utilizing a camera to decrease the noise of electron detection and a statistical approach to estimate particle orientations, the side-chain resolution barrier for membrane proteins without crystallization has recently been broken in a cryo-EM study of a transient receptor potential ion channel, TRPV1 (Liao et al., 2013).

Inherent in its nature, EM is a powerful experimental technique for distinguishing between structural symmetry and asymmetry in macromolecular complexes (Mi et al., 2011; Cerritelli et al., 2003; Hafenstein et al., 2007; Oshima et al., 2011; Cong et al., 2012; Matyskiela et al., 2013). It is important to note though that averaging and symmetry constraints used in EM often eliminate the chance of detecting oligomeric and small local asymmetries. Complementary information (XRC) and cross-validation can improve the evaluation of low-resolution cryo-EM data and prevent overfitting (Abrahams and Ban, 2003; Falkner and Schröder, 2013). 


\section{2d. Nuclear magnetic resonance (NMR) spectroscopy}

NMR spectroscopy provides structural information on the atomic scale in combination with dynamic insights of protein function (Cavanagh et al., 2006). Instrumental and methodological advances in the past decades (Pervushin et al., 1997; Gardner and Kay, 1998; Tjandra and Bax, 1997; Orekhov et al., 2001) opened the possibilities for the investigation of proteins up to $100 \mathrm{kDa}$ in the solution state (Tugarinov and Kay, 2003; Tugarinov et al., 2005), including the study of membrane proteins reconstituted in detergent micelles and bicelles (Sanders and Landis, 1995; Opella and Marassi, 2004). The most illustrative recent examples include the structure determination of a voltage-dependent anion channel from mitochondria, VDAC-1 (Hiller et al., 2008) and a GPCR-like seven-helical transmembrane receptor sensory rhodopsin II (Gautier et al., 2010).

Structure elucidation of dimers or higher oligomers by NMR is aided by special methodologies. In general, NMR spectroscopy in solution relies on the measurement of the nuclear overhauser effect (NOE), a phenomenon whose strength is proportional to the internuclear distance $\left(\sim \mathrm{r}^{-6}\right)$ between nuclear spins, conveniently between pairs of protons. For homooligomers, where it is often difficult to distinguish between intra- and intermolecular NOEs, special techniques such as isotope-filtered nuclear overhauser enhanced spectroscopy (NOESY) on mixtures of labelled and unlabelled proteins (Walters et al., 1997) or more recently methyl-NOESY pulse sequences in conjunction with methyl labelling techniques (Tugarinov et al., 2006) have been developed. Such methodologies have been used successfully to analyse the structure of the transmembrane (TM) and juxtamembrane segments of the epidermal growth factor receptor (EGFR) in lipid bilayers establishing a structural model for the asymmetric EGFR dimer (Endres et al., 2013) and to provide evidence for symmetry in a number of ligand-free homodimeric proteins that are either asymmetric functionally or according to XRC analysis, adopt different conformations of the two subunits (Godoy-Ruiz et al., 2011). Asymmetric methyl labelling can further improve the resolution of 
overlapping resonances in such studies as it has been demonstrated recently for the homopentameric membrane protein phospholamban (Traaseth et al., 2008). Structure determination of homooligomers can be additionally aided by the incorporation of paramagnetic probes into one of the monomers (Gaponenko et al., 2002). We note that problems arising from insufficient number of NOEs can also be overcome by the application of residual dipolar coupling-based molecular fragment replacement algorithms as demonstrated elegantly for a mitochondrial uncoupling protein (Berardi et al., 2011).

In addition to structure elucidation, NMR spectroscopy can be extremely valuable in the study of protein interactions in general. This is well exemplified by a recent study of the $\beta_{2^{-}}$ adrenergic receptor $\left(\beta_{2} \mathrm{AR}\right)$, where the high sensitivity of ${ }^{19} \mathrm{~F}$ nucleus to conformational changes has been exploited to prove the existence of parallel pathways for G-protein and $\beta$-arrestin signalling (Liu et al., 2012b).

An additional strength of NMR spectroscopy is that besides providing structural information at the atomic level, it can be used for the characterization of internal motions on a wide range of time scales (Jardetzky, 1996; Mittermaier and Kay, 2009). In particular, relaxation dispersion $\left(\mathrm{R}_{\mathrm{ex}}\right)$ NMR measurements (Loria et al., 1999) provide a way to capture transiently formed low-populated excited states in proteins not amenable by traditional structural approaches. This is well exemplified by a $\mathrm{R}_{\mathrm{ex}}$ analysis of the homopentameric $\mathrm{B}$ subunit of an $E$. coli toxin revealing an interconversion between an axially symmetric form and a low-abundance higher energy form (Yung et al., 2003). The advantage of $\mathrm{R}_{\mathrm{ex}}$ experiments is providing not only kinetic, but also thermodynamic, and structural information on transient states, which in turn can serve as new targets for allosteric inhibition and open new possibilities in drug design (Piana et al., 2002; Tzeng and Kalodimos, 2013). Another extensively investigated time regime in proteins is the ps-ns time scale (Farrow et al., 1994). The typically small-amplitude local fluctuations have a strong effect on entropy therefore on the thermodynamic stability of proteins and as shown by recent studies can be the source of 
negative cooperativity in protein-ligand interactions (Popovych et al., 2006). Additional NMR techniques are available to address motions in the intermediate and slow motional regime (Kleckner and Foster, 2011). Among them, ZZ-exchange has played a key role recently in a structural and dynamic investigation of the multidrug efflux transporter, EmrE, confirming an asymmetric antiparallel arrangement with two exchanging subunits (Morrison, 2012).

Despite the technological advances, due to slow molecular tumbling or restricted motion, structure elucidation of large multimeric complexes and membrane proteins in the solution state is still challenging. Solid-state NMR is a promising alternative for the investigation of these systems (Thompson, 2002; Opella and Marassi, 2004; Tapaneeyakorn et al., 2011; Weingarth and Baldus, 2013). For membrane proteins it has the additional advantage of allowing their investigation nearnative conditions in lipid bilayers or membrane extracts. As full structure determination still poses numerous challenges, solid-state NMR so far appears to be the most successful in addressing specific structural questions in complex biological systems. According to one approach, magnetically active spin labels (e.g. ${ }^{13} \mathrm{C},{ }^{15} \mathrm{~N},{ }^{19} \mathrm{~F}$ ) are incorporated into peptides/proteins and their interaction partners at strategically chosen positions, and by the measurement of homo- and heteronuclear dipolar couplings intra- and/or intermolecular distance restraints are established between the labelled positions (Thompson, 2002). Such distance measurements have yielded crucial structural information in the investigation of ligand induced conformational changes in receptors (Murphy et al., 2001; Isaac et al., 2002) and channels (Cady et al., 2011), elucidation of receptorbound ligand conformations (Williamson et al., 2007), determination of the depth of insertion (Doherty et al., 2010) and interhelical distance restraints (Smith et al., 2002) for membraneembedded channel-segments. Another approach involves the correlation of ${ }^{15} \mathrm{~N}-{ }^{1} \mathrm{H}$ dipolar coupling with the ${ }^{15} \mathrm{~N}$ chemical shift anisotropy of uniaxially aligned ${ }^{15} \mathrm{~N}$-labeled peptides/proteins allowing the determination of the tilt and rotational angle with respect to the membrane normal as shown for example for the voltage-sensor S4 helix of a potassium channel (Doherty et al., 2010). Additional 
solid-state NMR experiments, involving the characterization of site-specific ${ }^{2} \mathrm{H}$ relaxation of GPCR-bound ligands, have proven to be valuable in providing dynamic information on receptor activation in a membrane environment (Struts et al., 2011ab).

\section{2e. Electron paramagnetic resonance spectroscopy}

The high sensitivity of electron spins makes electron paramagnetic resonance (EPR) spectroscopy a popular tool for structural and dynamic investigations of large macromolecular complexes (Lakshmi and Brudvig, 2001). A further advantage of the technique is that experiments can be performed on non-crystallizable samples, making EPR particularly suitable for the study of membrane-bound signalling proteins. A limitation of EPR is its need for a selectively introduced paramagnetic spin label, which is typically achieved by site-directed nitroxide spin labelling (SDSL) (Hubbel et al., 2013). Multi-frequency EPR techniques in combination with lineshape analysis have been used extensively for structural and dynamic characterization of secondary structure elements (Borbat et al., 2001; Meirovitch et al., 2010) including a distinction between symmetric and asymmetric packing of TM helices in membrane proteins (Amadi et al., 2010). A drawback of pulsed EPR is that experiments need to be performed in the frozen state (typically around $70 \mathrm{~K}$ ) prompting an interest in the development and investigation of different freezing protocols on spin-label and protein conformation (Georgieva et al., 2012).

By taking advantage of the distance dependence of dipole-dipole interactions between two proximate paramagnetic spins, a number of single- and double-resonance EPR techniques have been developed for distance measurements (Berliner et al., 2000; Prisner et al., 2001). Among them, double site-directed spin labelling (DSDL) EPR techniques such as double electron-electron resonance (ELDOR) and its variants (Stehlik and Möbius, 1997) with the capability of the determination of intermediate and long-range distance restraints (10-70 ̊) between specific sites in proteins, are the most extensively used EPR methodologies to obtain information on the extent and 
directionality of conformational changes in large biomolecular complexes including homooligomers (Focke et al., 2011; Rice et al., 2013).

To complement long-range distance measurements, electron-nuclear double resonance (ENDOR) EPR techniques can be employed for inferring short-range distance restraints ( 4-5 $\AA$ ) (Prisner et al., 2001) with a potential to reveal asymmetries in binding geometry in protein-ligand interactions (Cohen et al., 2004).

\section{2f. Small angle $X$-ray and neutron scatterings}

Small angle X-ray scattering (SAXS) is a widely used experimental technique with a capability of providing low-resolution (10-50 ̊) structural information on macromolecular systems in solutions (Graewert and Svergun, 2013). Besides the near physiological experimental conditions, advantages of SAXS are: no size limitation, small amount of material ( $5-300 \mu \mathrm{g})$, and rapid measurements (within minutes). SAXS provides information on molecular shape, conformation, assembly state, aggregation, flexibility, and can be used predominantly as a complementary tool to high resolution techniques and single-molecule studies (Petoukhov and Svergun, 2007; Rambo and Tainer, 2013). For instance, SAXS in solution can verify physiologically relevant interfaces indicated by XRC, aid the evaluation of weak assemblies observed in crystals, and distinguish between alternative assemblies in different XRC structures (Putnam et al., 2007). Additionally, when high-resolution structures of individual subunits are available, it can be used to determine the relative orientation and position of subunits (Wall et al., 2000).

Studies of the transcription regulator CooA (Akiyama et al., 2004) and the response regulator (PrrA)-sensor kinase (PrrB) system from Mycobacterium tuberculosis (Nowak et al., 2006ab) illustrate that SAXS can also provide information on transient, ligand-induced conformational changes. Proteins with multiple conformations or with high flexibility are also well suited to analysis by SAXS. For instance, the complex of a pentameric histone chaperone with its 
heterodimeric carrier protein, importin $\alpha / \beta$, has been shown by SAXS to assume an architecture characterized with asymmetrically positioned importin dimers on the flexible tails of the pentamer (Falces et al., 2010). SAXS has also provided key structural evidence recently on the role of flexible hinge domains of nuclear hormone receptor heterodimers in establishing and maintaining an extended asymmetric shape for the receptor dimer upon coactivator binding (Rochel et al., 2011).

Similarly to neutron diffraction in crystallography, neutrons can also be used in solution scattering experiments. Small-angle neutron scattering (SANS) (Gutberlet et al., 2001) can be particularly useful in the study of detergent-solubilized membrane proteins as due to the difference in the interaction of neutrons with hydrogen and deuterium, the contribution of detergent molecules can be eliminated (Johs et al., 2006). Deuterium-assisted SANS has also proven to be valuable for a real-time exploration of exchange processes in oligomeric systems (Sugiyama et al., 2011).

\section{2f. Mass spectroscopy}

Advances in electrospray ionization (ESI) and matrix-assisted laser desorption/ionization (MALDI) has made mass spectroscopy (MS) a powerful tool to assess the architecture, connectivity, evolution, asymmetry of even large multidomain complexes (Bich and Zenobi, 2009; Levy et al., 2008; Kirshenbaum et al., 2010; Sharon, 2013). No requirement for crystals, low sample need (pmol) and short measurement time (min) allowing high-throughput processing are considered to be the main strengths of MS. As it has been shown recently, nanoflow ESI-MS studies can distinguish coexisting protein populations with different number of bound ligands (nucleotides for ATPases) and determine the rank order of binding affinities and the role of transient asymmetries of higher-order ring systems in the function of chaperonins and transcription activators (Dyachenko et al., 2013; Zhang et al., 2014).

Among the numerous applications of ESI, monitoring hydrogen/deuterium (H/D) exchange is a frequently used approach for the characterization of solvent exposure and conformational 
changes in signalling proteins. For instance, in an investigation of the type-I insulin-like growth factor receptor, analysis of H/D exchange rates of proteolytically derived peptides has shown two distinct populations of active state conformations confirming the structural asymmetry of the homodimeric receptor (Houde and Demarest, 2011). MS-based footprinting via H/D exchange or side chain labelling can also detect interface asymmetries as shown for EGF receptor dimers (Collier et al., 2013)

Ion mobility spectrometry coupled with MS (Ruotolo et al., 2008) extends the information content of MS analyses e.g. for intrinsically disordered regions of signalling proteins (Jurneczko et al., 2012). Furthermore, by allowing the investigation of collision cross-sections, it provides not only mass-to-charge ratios and the stoichiometry of subunits, but also the size and shape of macromolecular assemblies (Ruotolo et al., 2005).

For macromolecules, which are difficult to ionize, the application of MALDI may provide an alternative for ESI (Bolbach, 2005). Besides its high salt tolerance, the main advantage of MALDI is that it predominantly produces single-charged ions leading to simplified spectra. The combination of MALDI-MS with chemical cross-linking to achieve higher stabilization and the availability of high-mass detectors enable the structural, thermodynamic, and kinetic investigations of receptors (Riek et al., 2008).

\section{2h. Methodical comparison of biophysical techniques}

Networks of weak and reversible noncovalent interactions dominate the fine structures and conformational changes of signalling proteins. The biophysical methods discussed above and compared in Table 1, in combination with complementary methods of biochemistry, molecular biology and electrophysiology, can elucidate the mechanistic details of these interactions. Cryo-EM and XRC offer static pictures of shape and low-energy conformations of macromolecules. XRC has maintained a dominant role in providing atomic-level structural information, especially with the 
introduction of lipidic meso phase crystallization, which can capture membrane-embedded signalling proteins in functionally relevant states. With the increasing resolution of XRC and cryoEM structures, symmetry constraints can be presumably omitted so that local asymmetries can be detected. Although under specific conditions XRC may reveal transient states of functional relevance, by its very nature tend not to reveal the flexibility of proteins. EPR and in particular NMR have the capability of assessing dynamic information on a wide range of time scales, with the latter being able to provide structural, thermodynamic, and kinetic information on functionally relevant, low-populated, excited states. An additional advantage of both techniques for membrane proteins is that they can be investigated in near-native conditions (i.e. bicelles, lipid bilayers). Unfortunately, size-limitation and expression of isotope-labelled proteins in quantities suitable for NMR experiments can still pose a challenge. FRET/BRET has an enormous advantage of low sample need and high sensitivity allowing the characterization of protein interactions both under in vitro and in vivo conditions and despite its limitations, it appears currently the most versatile and promising technique for uncovering symmetry violation and asymmetric perturbations in signalling proteins. Additionally, based on the pioneering achievements of Karplus, Levitt, Warshel, and others, a combination of classical and quantum physics has led to MD simulations of chemical interactions for macromolecules including signalling proteins (Levitt, 2001). Protein databases have become richer and offer a better choice of proper starting structures for MD simulations. With rapid progress in computation, MD simulations are approaching the $\mu$ s timescale of signalling events. Consequently, they can elucidate asymmetric transition states with increasing reliability. These virtual asymmetries should be confirmed by a suitable combination of biophysical methods. 


\section{Structural symmetry and transient asymmetry of signalling proteins}

\section{3a. Dimeric GPCRs, growth factor receptors and transcription factors}

Dimers are the most prevalent oligomers (Goodsell and Olson, 2000). Although most homodimers are symmetric, 1:2 ligand binding (to half of the sites) is usually a source of asymmetry (Miguez, 2010; Swapna et al., 2012). Binding to either of two identical sites results in negative cooperativity and decreased affinity to the second site (see $\mathrm{K}_{\mathrm{d}}$ in Fig. 1).

The family of $\mathbf{G}$ protein-coupled receptors (GPCRs) include several signalling proteins such as receptors of crucial neurotransmitters (acetylcholine, adrenalin, dopamine, $\gamma$-aminobutyric acid, glutamate, histamine), secondary transmitters (cyclic nucleotides, phosphatidylinositol), hormones (glucagon, melatonin, prostaglandins, neuropeptides, growth factors and lipids). Further, they mediate the perception of pain, light, odour, and taste. GPCRs form symmetric homodimers and pseudosymmetric heterodimers. Selective labelling and FRET enable us to distinguish between the roles of individual subunits. Moreover, XRC has revealed the structures of several class A (rhodopsin-like) GPCRs in functional complex with G proteins and ligands of different efficacies (Rasmussen et al., 2011a). Ligands bind in-between the transmembrane (TM) helices of class A and B, while in a large Venus flytrap EC domain of class C GPCRs, respectively. GPCR dimers exhibit asymmetry at different levels as summarized below (i-iv) (Fig. 1) (Maurice et al., 2011). i) Agonists bind to either of the two subunits and with different affinities. As shown by XRC of a ligandbinding EC domain, agonist binding closes the Venus flytrap domain of class $\mathrm{C}$ metabotropic glutamate receptor subunits with asymmetric rearrangements as revealed by XRC of the ligandbinding EC domain (Kunishima et al., 2000). ii) Several reports have concluded that ligand binding can elicit not only cis but also trans activation via the TM helices. However, fluorescence labelling and radioligand binding have revealed only cis activation for chimeric heterodimers of rhodopsinlike leukotriene $\mathrm{B}_{4}$ receptors (Damian et al., 2008). Asymmetric activation was reported for $\mathrm{G}$ 
protein-fused dopamine $\mathrm{D}_{2}$ receptor homodimers via functional complementation experiments (Han et al., 2009). Agonist binding to a single protomer induced full activation. An inverse agonist enhanced signalling, whereas another agonist inhibited it together with symmetry restoration. iii) $G$ protein binding to the IC side of only one subunit of GPCRs also results in asymmetric functioning as detected by fluorescence for a leukotriene $\mathrm{B}_{4}$ receptor dimer with a single tryptophan-labelled protomer (Damian et al., 2006). The other subunit can bind other GPCR-interacting proteins, arrestins or regulators leading to further differences in down-stream signalling (Rovira et al., 2009). This was observed for melatonin $\mathrm{MT}_{1}$ receptor homodimers coupled to $\mathrm{G}_{\mathrm{i}}$ proteins and to a regulator of $\mathrm{G}$ protein signalling via radioligand binding and BRET measurements (Maurice et al., 2010). Arrestin, a mediator of GPCR desensitization, binds to phosphorylated opsin and induces asymmetric binding of the agonist trans-retinal to these class A GPCR subunits in 1:2:1 ratio (Sommer et al., 2012). iv) Finally, pseudosymmetric heteromeric GPCRs create further asymmetry. Different functional states of the subunits were concluded a) from the XRC of the EC domain of GBR2 subunits, mutational analysis, and radioligand binding of class $\mathrm{C} \mathrm{GABA}_{\mathrm{B}}$ receptors (Geng et al., 2012); and b) from the different roles of T1R subunit domains in ligand recognition and $G$ protein coupling of taste receptors (Xu et al., 2004). Also, allosteric modulators of heterodimeric metabotropic glutamate receptors exert different efficacies depending on which subunit they bind to (Goudet et al., 2005). Asymmetric activation of 5-HT2C-type seronin and oxytocin class A GPCRs was also demonstrated with disulphide-trapping and radioligand binding as well as with timeresolved FRET and living cells, respectively (Albizu et al., 2010; Mancia et al., 2008)

The growth factor receptor family belongs to tyrosine kinases activated by ligand-induced dimerization. The asymmetric dimerization of epidermal growth factor receptors (EGFRs) has been thoroughly studied via XRC and mutational analysis. The XRC of EC and IC domains revealed that i) the C-lobe of the donor kinase domain asymmetrically interacts with the N-lobe of the acceptor domain (Zhang et al., 2006) and ii) an IC juxtamembrane segment (latch) is crucial for dimerization 
of the kinase domains and activation (Jura et al., 2009). Fluorescent ligand-binding assays demonstrated that the first EGF binding promotes an asymmetric dimerization interface (Alvarado et al., 2010). As a result of EGF binding to a luciferase-labelled heterodimer the cis-kinase adopted the acceptor position in the asymmetric dimer and was activated first (Macdonald-Obermann et al., 2012). It was concluded from ${ }^{125}$ I-EGF binding studies that the membrane-proximal IC domain is responsible for the negative cooperativity of ligand binding to the second site, which reorients the asymmetric dimer from the initial to reciprocal conformation (Adak et al., 2011). Inactive symmetric kinase dimers were also demonstrated by cryo-EM (Mi et al., 2011). Furthermore, MD simulations show that in ligand-bound EGFR dimers, the $\mathrm{N}$ - and the C-terminal TM dimers represent an active and an inactive conformation, respectively, in which the $\mathrm{N}$-terminal portions of the juxtamembrane segments form antiparallel helix dimers leading to an asymmetric transition state (Arkhipov et al., 2013). Comparative XRC structures can explain why the mono-liganded asymmetric form may be more common to Drosophila than to the human EGFRs (Liu et al., 2012a; Perilla et al., 2013). Importantly, asymmetric kinase dimer formation is essential for activation of wild-type and oncogenic mutant EGFRs but not for kinase phosphorylation (Zhang et al., 2006; Kancha et al., 2013).

The dimerization of other kinase receptors has been found similarly asymmetric. XRC of the heparin-bound ectodomain of fibroblast growth factor (FGF) receptor kinase FGFR2 showed that heparin elicits asymmetric homodimerization of the FGF1/FGFR2 complex (Pellegrini et al., 2000). H/D exchange and peptide mass mapping have revealed asymmetric dimerization of type-I insulinlike growth factor receptors (IGF-1R) by IGF (Houde and Demarest, 2011). Neurotrophins including nerve growth factors (NGFs) participate in the development of the vertebrate nervous system. They induce homodimerization of glycosylated p75 neurotrophin receptors $\left(\mathrm{p} 75^{\mathrm{NTR}}\right)$ with controversial symmetry. Asymmetric $2: 1$ complexes of $\mathrm{NGF} / \mathrm{p} 75^{\mathrm{NTR}}$ were demonstrated first via XRC of the ectodomain of p75 (He and Garcia, 2004). However, symmetric 2:2 complexes of 
$\mathrm{NT} 3 / \mathrm{p} 75^{\mathrm{NTR}}$ were reported later (Gong et al., 2008). NGF is synthesized from its precursor, proNGF. XRC of the proNGF/p75 ${ }^{\mathrm{NTR}}$ complex and multi-angle light scattering in solution demonstrated a 2:2 symmetry which was attributed to conformational changes of the pro regions of proNGF (Feng et al., 2010). Mature NGF and proNGF are known to initiate opposing responses. Consequently, different NT-induced conformational changes result in different $\mathrm{p} 75^{\mathrm{NTR}}$ symmetries and mediate distinct signalling activities. It should be emphasized that all these asymmetric noncovalent interactions serve as prerequisites of the first covalent interaction of tyrosine autophosphorylation (Bae et al., 2010). NGF-like cytokine Spätzle dimers bind to the Drosophila immunoreceptor Toll with similar asymmetric arrangement and same stoichiometry as NGF/p75 ${ }^{\mathrm{NTR}}$ (Lewis et al., 2013).

There are various families of bacterial transcription factors that link sensor function to gene expression modulation. Histidine sensor kinase receptors participate in bacterial quorum sensing. The autoinducer Al-2 binds to the periplasmic binding protein LuxP of Vibrio harveyi, elicits domain closure, asymmetric dimerization of LuxPQ complexes, and represses the kinase activity of LuxQ as concluded from XRC of Al-2-bound LuxPQP and luciferase bioassays (Neiditsch et al., 2006). Interestingly, kinase and phosphatase activities of the dimeric complexes of receptor sensor domains have been correlated with symmetry switches (Moore and Hendrickson, 2012). Fig. 2 shows that kinase activity is associated with symmetric, whereas phosphatase activity with asymmetric dimers.

Catabolite activator protein (CAP) is a further classic example of an allosteric transcriptional regulator of several metabolic operons in E. coli. The CAP homodimer is activated by IC cAMP. Each subunit contains a cAMP-binding domain (CBD) mediating dimerization and a DNA-binding domain (DBD). cAMP elicits a coil-to-helix transition in CAP positioning the recognition helices in the DBDs in the appropriate orientation interacting with the successive major groves of DNA (Popovych et al., 2009). The symmetric CAP dimer binds two molecules of cAMP 
with strong negative cooperativity. As revealed by NMR chemical shift analysis of the three complexes: apo $\mathrm{CBD}_{2}$, cAMP $1-\mathrm{CBD}_{2}$, and $\mathrm{cAMP}_{2}-\mathrm{CBD}_{2}$, the mono-liganded species corresponds to an asymmetric intermediate in which the conformation of the nonliganded subunit matches the conformation of the apo protein, whereas the conformation of the liganded subunit matches that of the di-liganded state (Popovych et al., 2006). Intriguingly, while there are no long-range structural effects of the binding of the first cAMP, its presence induces a conformational exchange on the ms time scale through the entire dimer, a motion which ceases upon binding of the second cAMP. In contrast to the ms motions, changes in the ps-ns flexibility of the protein backbone upon the first binding step are small and confined to the binding site of the liganded subunit. However, binding of the second cAMP results in a widespread rigidification of the protein backbone on the ps-ns timescale in both subunits (Popovych et al., 2006). This corresponds to unfavourable backbone conformational entropy, a predominant source of negative cooperativity of the cAMP-CBD interaction as shown by NMR relaxation and calorimetric measurements. Conformational entropy appears to play a key role in CAP-DNA interaction as well. NMR dynamic study of a CAP-cAMP 2 mutant exhibiting an inactive conformation in its effector-bound state shows that its strong affinity for DNA arises from enhanced protein motions induced by DNA binding (Tzeng and Kalodimos, 2009).

In summary, most dimeric proteins including the signalling ones discussed above have closed (face-to-face) C2 symmetries (Levy et al., 2008). Ligand binding to one subunit can trigger conformational changes of the dimer affecting asymmetrically the binding affinity of the two subunits. Alternatively, binding in the interface of subunits can result in an asymmetric reorganization of the dimer. Both of these perturbations elicit various functional consequences of signal transduction. 


\section{3b. Trimeric acid-sensing ion channels and tetrameric voltage-gated cation channels, ionotropic glutamate receptors, viral proton channels, CNG and CHN channels.}

Closed, face-to-back oligomerization can lead to channels with rotational symmetry. Chemical (ligand) and physical (electric and mechanic) signals open the membrane channels for passive ion transport along the ion concentration gradients. Acid-sensing ion channels (ASICs) are symmetric homotrimers as shown via XRC of ASIC1A-psalmotoxin complexes (Baconguis and Gouaux, 2012). In contrast, $\mathrm{XRC}$ at low $\mathrm{pH}$ demonstrated rearranged TM helices and asymmetric opening of a $\mathrm{Na}^{+}$-selective channel.

The follicle-stimulating hormone (FSH), a prototype of glycoprotein hormones, binds to class A GPCRs. The FSH receptor exists as a trimer. FSH binding activates one protomer. This seems to lead to an asymmetric switch of the trimer to active state and G-protein binding (Jiang et al., 2014). The three-fold symmetry of transporters will be discussed later.

Four protomers offer greater variability. Tetrameric voltage-gated sodium channels initiate action potentials. The bacterial $\mathrm{NaChBac}$ family is a useful model of vertebrate voltage-gated ion channels. NaChBac channels are homotetramers of subunits containing six TM segments (S1-S6). A comparison of the XRC structures of bacterial NavRh and NavAb showed structural asymmetry for the activated voltage-sensing domains (S1-S4) and the EC entrance of the selectivity filter (Payandeh et al., 2011; Zhang et al., 2012). Based on XRC snapshots of two inactivated states of NavAb, the S6 segments seem to collapse asymmetrically into a dimer-of-dimers conformation at the activation gate (Payandeh et al., 2012). Single channel electrophysiology of an inactivationdeficient eukaryotic Nav1.4 channel has recently supported the asynchronous activation movements of voltage sensors and the pore domain (Goldschen-Ohm et al., 2013).

Ionotropic glutamate receptors (iGluRs) mediate excitatory neurotransmission. Various skew, Y-like shapes of AMPA-type iGluRs by cryo-EM have been attributed to different conformational states (Nakagawa et al., 2005). Pioneering XRC, mutational, cross-linking, and 
binding studies revealed a complex symmetry mismatch of the homotetrameric rat GluA2 receptor: two-fold symmetry of the N-terminal and ligand-binding EC domains and four-fold rotational symmetry of the channel domain (Sobolevsky et al., 2009). Consequently, the two pairs of subunits are coupled to the channel gate with distinct stereochemistry.

Cyclic nucleotide-gated (CNG) ion channels mediate sensory signal transduction in photoreceptors and olfactory cells. Binding of a fluorescent cGMP analogue to olfactory-type homotetrameric CNGA2 channels showed that the second ligand binds with strong negative cooperativity, leads to asymmetry and elicits full opening (Biskup et al., 2007). In heterotetrameric, thus asymmetric native CNG channels, odorants could elicit stronger effects than in homomeric CNGA2 channels (Chen et al., 2006). Hyperpolarization-activated, cyclic nucleotide-modulated $(\mathrm{HCN})$ channels with pacemaker activity are primarily voltage-activated and additionally facilitated by cAMP binding at the cyclic NB IC domain. It was concluded from a confocal patch-clamp fluorometric study that zero and four cAMP (thus symmetric) bindings result in greater stability of homotetrameric HCN2 channels than one- and three-liganded channels (Kusch et al., 2012). It should be noted that for cyclic homotetramers and dimers of dimers, symmetry mismatch can lead to lower-degree symmetry.

In another example, a subtle $\mathrm{pH}$-dependent symmetry breaking is observed via $\mathrm{XRC}$ in homotetrameric M2 proton channels of the influenza A virus (Stouffer et al., 2008). At low pH all four helices stand straight near the C-terminal gate of the channel forming a wide, symmetric exit funnel, whereas at neutral $\mathrm{pH}$ one of the helices bends and forms a salt bridge and aromatic interactions with a neighbouring helix leading to pore occlusion. Low $\mathrm{pH}$ results in electrostatic repulsion between protonated histidines shifting the equilibrium toward the open state. The bend near Gly $y_{34}$ and the aromatic interactions between neighbouring helices involving His ${ }_{37}$ and $\operatorname{Trp}_{41}$ were previously predicted by solid-state NMR experiments (Nishimura et al., 2002). 


\section{3c. Pentameric ligand-gated and mechanosensitive channels}

Five-fold rotational symmetry with an odd number of participating protomers might seem less symmetric. In fact, it is the least abundant among symmetric proteins (Levy et al., 2008). Still, this symmetry is overrepresented among physiologically and pharmacologically important signalling proteins including the superfamily of pentameric ligand-gated ion channels (pLGICs) with a characteristic Cys-loop. Evolutionary diversification of pLGICs has led to distinct families activated by important neurotransmitters of excitatory (acetylcholine and serotonin) and inhibitory types ( $\gamma$-aminobutyric acid and glycine). Neuromuscular nicotinic acetylcholine receptors served as a lead to reveal pseudo-symmetric pentamers via cryo-EC and then agonist-elicited differences in the conformations of subunits via fast-freezing and electrospray techniques on the ms time scale (Unwin, 1995, 2005). Great varieties of the homologous subunits and their pentameric assemblies have resulted in great structural and functional heterogeneities within most families of (pseudo)symmetric pLGICs. Therefore it is a huge challenge to design subtype-selective allosteric agents for pLGICs, e.g. anaesthetic alcohols as well as anxiolytic, sedative, and hypnotic compounds acting via the benzodiazepine binding sites of A-type GABA receptors $\left(\mathrm{GABA}_{\mathrm{A}} \mathrm{Rs}\right)$. Low $(n M-\mu M)$ concentrations of these allosteric agents potentiate agonists to open $\mathrm{GABA}_{\mathrm{A}} \mathrm{R}$ channels, whereas $\mathrm{mM}$ concentrations of agonists and these allosters desensitize and block the channels. Enormous efforts to put this pharmacological challenge on a structural basis have resulted in the XRC structures of three pLGICs: the prokaryotic ion channels ELIC and GLIC as well as the eukaryotic glutamate-gated chloride channel GluCl (see in Fig. 3 and a recent review of Nys et al., 2013). Even though these homopentamers have proven to be good pLGIC models (Spurny et al., 2012), crystallization in the presence of saturating ligand concentrations has resulted in XRC structures with open or closed pore states not compatible with the functional effects of cocrystallized ligands (Gonzalez-Gutierrez et al., 2012). Furthermore, the XRC structures have revealed a perplexing heterogeneity of inter- and intra-subunit binding cavities both for anaesthetics 
in the TM domain and for benzodiazepines in the EC domain (Spurny et al., 2012; Spurny et al., 2013). For ELIC, a pharmacologically relevant model of $\mathrm{GABA}_{A} \mathrm{R}$ potentiation, in the presence of potentiating, low benzodiazepine concentrations, XRC has yielded a structure with occupancy of only one intrasubunit EC binding site adjacent to a GABA-binding interface (Spurny et al., 2012). The asymmetric ligand perturbations in Fig. 3 match the pattern of agonist occupancies in three nonconsecutive EC interfaces of a chimeric pLGIC homopentamer resulting in maximal channel opening (Rayes et al., 2009). MD simulations of GLIC with only asymmetric patterns of the anaesthetic propofol bound at identical TM sites elicited asymmetric state transitions for channel closure (Mowrey et al., 2013). In addition to anaesthetic binding, flexibility of TM binding regions also seems to be required for functional transitions. Both anaesthetics, halothane and ketamine bind in a TM cavity of the $\alpha 7$ nicotinic acetylcholine receptor, another functional pLGIC homopentamer, but only ketamine inhibits its function. Solution NMR spectroscopy has recently revealed that only ketamine induces dynamic changes of the TM region of the $\alpha 7$ channel and perturbed a gate residue (Bondarenko et al., 2014). Thus, the selective effects of ketamine can be attributed to distinctive entropic gains of the heterogeneous TM transition states. In summary, unbalanced forces of ligand perturbation of pLGICs with rotational asymmetry facilitate state transitions in channel gating (Maksay, 2013).

Mechanosensitive (MS) channels act to signal touch, hearing, proprioception, plant turgor and bacterial osmoregulation. Ions, metabolites and water can cross these channels opened by local and global lateral membrane pressures, transbilayer asymmetries (e.g. curvatures) and proteinbilayer hydrophobic mismatches. Homopentameric large conductance MS channels of Escherichia coli (MscL) are the best studied models (Perozo et al., 2002ab). It was demonstrated via EPR that asymmetric incorporation of lysophosphatidylcholine into phosphatidylcholine vesicles resulted in iris-like rotation and tilt of the TM helices of MscL channels. By changing the hydrophobicity of a pore-lining TM1 moiety at the hydrophobic gate and using fluorescence labelling, it was elegantly 
demonstrated that the hydrophobicity of a single TM1 domain initiates MscL gating, and the contribution of other TM helices is asymmetric (Birkner et al., 2012). This type of asymmetric perturbation of membrane lipids and MscL by phospholipase $A_{2}$ has been recently exploited to engineer signalling networks (Charalambous et al., 2012).

Bacterial CorA is an important model system for eukaryotic $\mathrm{Mg}^{2+}$ channels. The XRC structure of $\mathrm{Mg}^{2+}$-bound CorA revealed a transport-incompetent symmetric homopentamer, with $\mathrm{Mg}^{2+}$ asymmetrically coordinated in the pore (Pfoh et al., 2012). On the other hand, in the absence of $\mathrm{Mg}^{2+}$, "bell-bending", lateral, and radial TM motions increased the asymmetry and unlocked the channel.

In summary, various oligomeric channels have rotational, closed symmetry (C3-C5) where all interfaces are face-to-back. Physical or chemical signals trigger symmetry breaking and facilitate channel gating, which enable passive membrane transport and further processes of transduction.

\section{3d. Higher order oligomers: hexameric gap junction channel, chaperonins, proteasome and virus capsid.}

Gap junctions are multifunctional, voltage-dependent channels for the intercellular exchange of metabolites. Symmetry-constrained XRC structures disclosed two symmetric hemichannels formed by four TM helices of six protomers of connexin 26 (Maeda et al., 2009). In contrast, cryoEC has shown asymmetric hexamers with radial outward tilting of TM helices and inside bending of the N-terminal plug of the pore (Oshima et al., 2011).

Chaperonins are nanomachines facilitating protein folding driven by ATP hydrolysis. They form a barrel of two rings containing 7-9 subunits. The model system of group I chaperonins, GroEL of E. coli is a symmetric double-ring 14-mer and the co-chaperonin heptamer GroES is the lid of this barrel. SAXS could distinguish between the biological relevance of symmetric and asymmetric configurations of the GroEL-GroES complex (Inobe et al., 2008). A recent comparative 
$\mathrm{XRC}$ and cryo-EM study has revealed that functional transition of GroEL into a relaxed state is associated with breaking of two salt bridges and transient asymmetry of the apical domains (Fei et al., 2013). Asymmetries can be also revealed in the octameric rings of TRiC, an eukaryotic group II chaperonin; in its ATP-binding hierarchy; and even in its transition states (Cong et al., 2012; Reissmann et al., 2012).

The 26S proteasome is the major eukaryotic ATP-dependent protease for the degradation of ubiquitin-tagged proteins. Its barrel-shaped $20 \mathrm{~S}$ peptidase is capped by a $19 \mathrm{~S}$ regulator, a heterohexamer of Rpt subunits. Complex chemical modification and MS studies revealed that binding of $19 \mathrm{~S}$ is mediated by the C-termini of only two Rpt subunits to dedicated sites on the proteasome and play nonequivalent roles in the asymmetric assembly and activation of the $26 \mathrm{~S}$ proteasome (Gillette et al., 2008). Cryo-EM has shown that substrate-induced rearrangement of the ATPase subunits results in seven-fold symmetry of the peptidase barrel (Matyskiela et al., 2013). Deuteration-assisted SANS was applied to the tetradecamer of the proteasome $\alpha 7$ subunits and showed kinetic asymmetry in the exchange of only two subunits (Sugiyama et al., 2011).

Symmetry breaking in capsid assembly of viruses with cubic symmetry and in viral infection has been revealed by cry-EM long ago (Steven et al., 1997). Symmetry mismatch at the portal vertex of bacteriophage $\mathrm{T} 7$ facilitates rotation and ring separation in capsid maturation and DNA packaging (Cerritelli et al., 2003). The cellular harbour of parvovirus, the dimeric transferrin receptor can bind to only a few of the 60 icosahedrally equivalent sites on capsids (Hafenstein et al., 2007). MD simulations have confirmed the asymmetric transition states of maturation of the tubular and spherical arrangements of hexameric and pentameric oligomers of bacteriophage HK97 and HIV-1 capsids (May et al., 2012; Zhao et al., 2013). 


\section{3e. Primary and secondary transporters}

Intake of nutrients and removal of toxic wastes are regulated by a complex network of sensing and signalling mechanisms in cells and have a key role in cellular adaptation to environmental conditions. The intimate relation of transport and signalling processes is further suggested by a discovery that some of the membrane transporters also act as receptors (Holsbeeks et al., 2004; Popova 2010; Kriel et al., 2011). Unlike channels, transporters translocate their substrates against a concentration gradient. While primary active transporters use chemical energy (ATP hydrolysis, redox reaction) or light to drive the thermodynamically unfavourable transport of their substrates, secondary active transporters are driven by the electrochemical gradients of the transported species by symport or antiport mechanisms. Although transporters mediate the trafficking of a broad range of substrates and can be classified into distinct structural families, they appear to share a common mechanistic scheme of alternating access (AA). According to this, the substrate-binding cavity is shuttled along the membrane normal and is alternatively exposed to the EC and IC side of the lipid bilayer, corresponding to outward-facing (OFS) and inward-facing states (IFS) of the transporter, respectively (Fig. 4). While in ATP-binding cassette (ABC) transporters, a ubiquitous family of primary transporters, AA is achieved by the motion of the two TM domains coupled to the association and dissociation of the two NB domains (Davidson \& Maloney, 2007; Hollenstein et al., 2007; Sonne et al., 2007; Chen, 2013), in secondary transporters such as neurotransmitter transporters, isomerisation between an inward- and outward facing state is thought to occur by swapping the conformations of symmetry-related structural domains (Forrest et al, 2008).

Association and dissociation of the NB domains in the $\mathrm{ABC}$-carrier family of primary transporters is brought about by the binding and hydrolysis of ATP. While in prokaryotic ABCtransporters the two TM and two NB domains usually come from the same gene resulting in mostly identical homodimers, in eukaryotic cells the respective domains are coded by different genes 
forming a heterodimer (Biemans-Oldehinkel et al., 2006). The genetically encoded asymmetry in eukaryotic ABC-transporters is manifested in two non-equivalent ATPase sites. While in one of the NB domains the ATPase site is formed by consensus residues, in the other NB domain it contains non-consensus substitutions in one or more conserved motifs (Procko et al., 2009). However, the asymmetry of NB domains is not limited to heterodimeric eukaryotic ABC-transporters. XRC analysis of haemolysin HlyB, a key element of the Type I secretion machinery in E. coli, has shown evidence of asymmetric monomer-monomer interactions in the ATP-bound form of the NB-HlyB homodimer, resulting in one closed and one open phosphate exit tunnel within the dimer (Zaitseva et al., 2006). Asymmetry of bacterial ABC-transporters is also evidenced by interaction with designed ankyrin repeat proteins (DARPin) as shown for MsbA, an ABC exporter responsible for lipid A transport in E. coli (Mittal et al., 2012). Interestingly, the DARPin binding sites have been mapped to the TM domain of MsbA, suggesting that the asymmetries in the NB and TM domains are conformationally linked. MD simulations of Sav1866, another homodimeric bacterial ABCtransporter, supports the occurrence of asymmetric NB domain transitions in the prehydrolytic state (Aittoniemi et al., 2010; Gyimesi et al., 2011). Intriguingly, many of the charged residues involved in asymmetric conformational switching in Sav1866 (Aittonieni et al., 2010) correspond to residues located in degenerate motifs in heterodimeric eukaryotic ABC-transporters (Procko et al., 2009). MD simulations also indicate an asymmetric post-hydrolysis state manifested in one open and one occluded active site in the NB homodimer (George and Jones, 2013). These studies indicate a sequential rather than concerted mechanism of ATP hydrolysis for prokaryotic ABC-transporters (George and Jones, 2012). Hydrolysis at the first site is thought to bring about a conformational change allowing the subsequent hydrolysis of the second ATP at the other site (Campbell and Sansom, 2005). Unlike in higher organisms, where the question of which site goes first is determined by genetically encoded asymmetry, in prokaryotes the order appears to be stochastic at each transport cycle (Procko et al., 2009). 
While in exporters ATP-hydrolysis is initiated by a direct interaction between the substrate and the TM domains, in importers ATPase activity is stimulated by a substrate-loaded binding protein. It is under debate whether interaction with the latter may be a source of symmetry loss in homodimeric $\mathrm{ABC}$-importers. $\mathrm{BtuC}_{2} \mathrm{D}_{2}$ is an $\mathrm{ABC}$-carrier that transports $\mathrm{B}_{12}$ vitamin from the periplasmic binding protein BtuF into the cytoplasm of E. coli (Reynolds et al., 1980). The interface between $\mathrm{BtuF}$ and the two TM domains of the transport protein $\left(\mathrm{BtuC}_{2}\right)$ involves two nonidentical lobes of BtuF, each contacting primarily one BtuC subunit. While in the structure of $\mathrm{BtuC}_{2} \mathrm{D}_{2}$ the two TM domains are related by a two-fold rotational symmetry (Locher et al., 2002), $\mathrm{BtuC}_{2} \mathrm{D}_{2} \mathrm{~F}$ is characterized by a marked asymmetry involving several TM helices (Hvorup et al., 2007). As a result of the movement of the TM helices, the translocation pathway becomes inaccessible to both sides of the membrane suggesting an asymmetrically occluded posttranslocation intermediate. In a recent $\mathrm{XRC}$ analysis of a hydrolysis-deficient $\mathrm{BtuC}_{2} \mathrm{D}_{2}$ mutant in complex with $\mathrm{BtuF}$, the orientation of BtuF relative to the $\mathrm{BtuC}_{2}$ dimer has been found to be rotated by $180^{\circ}$ indicating that the TM domains may adopt either of the two asymmetric conformations in nucleotide-free BtuC $_{2} \mathrm{D}_{2} \mathrm{~F}$ (Korkhov et al., 2012a). While the role of BtuF in the observed asymmetry remains to be uncertain, the posttranslocation intermediate with the closed cytoplasmic gate has been suggested to have a biological implication of preventing the leakage of small molecules at the end of the transport cycle (Korkhov et al., 2012b).

Despite the differences in amino acid sequence and functionality, many of the subfamilies of secondary active transporters appear to be evolutionarily and structurally related (Lolkema and Slotboom, 2003; Theobald and Miller, 2010). A common characteristic of secondary transporters is the presence of structural repeats comprised of several TM segments assuming a specific threedimensional fold (Boudker and Verdon, 2010). Structural repeats may assemble in either parallel or antiparallel orientations giving rise to pseudo-symmetry axis parallel or perpendicular to the membrane normal, respectively. Transition from the OFS to the IFS is thought to be accomplished 
via a combination of rocking movements of symmetry-related protein domains and local motions of EC and IC gates (Krishnamoorthy et al., 2009). High-resolution structure elucidation of secondary transporters comprised of multiple identical subunits in a growing number of cases leads to capturing snapshots of different physiological states of the same protein corresponding to intermediate conformations of the translocation process, indicating that transition between the OFS and the IFS is not a two-state process. These transporter intermediates can often be described as asymmetric homooligomers with their protomers being in different conformational states. This is well exemplified by a recent XRC analysis of a functional double mutant of $\mathrm{Glt}_{\mathrm{Ph}}$, a glutamate transporter from Pyrococcus horikoshii (Verdon and Boudker, 2012). While previous structure determinations captured Glt ${ }_{\mathrm{Ph}}$ (Yernool et al, 2004; Boudker et al. 2007) and its analogue (Reyes et al., 2009) as symmetric trimers with all their protomers facing either outward or inward, the structure of the $\mathrm{Glt}_{\mathrm{Ph}}-\mathrm{V} 198 \mathrm{CA} 380 \mathrm{C}_{\mathrm{Hg}}$ double mutant is an asymmetric trimer with two protomers in IFS and one in an intermediate outward-facing state (iOFS) (Fig. 4A). The transition from the OFS to the iOFS has been shown to involve conformational changes in both the core and the scaffold of the transporter, consequently in both the transport and the trimerisation domains, including a translation and rotation of the first and concerted tilting of several $\alpha$-helices in the latter (Fig. 4B4C). The independent nature of individual subunits in glutamate transporters is also supported by electrophysiological and FRET measurements (Grewer et al., 2005; Koch and Larsson, 2005; Leary et al., 2007; Erkens et al., 2013) as well as chemical cross-linking studies of substrate transport (Groeneveld and Slotboom, 2007). Intriguingly, the binding of co-substrate sodium shows positive cooperativity between individual protomers (Koch et al., 2007). Also, conformational changes accompanying glutamate and sodium binding and/or translocation are transmitted to distant regions of the transporter located in the vicinity of the subunit interface (Koch et al., 2007). As it has been indicated, the corresponding TM3-TM4 EC loop plays a vital role in the transport process in Glt $\mathrm{Ph}_{\text {, }}$ specifically, in the opening of the EC gate (Compton et al., 2010). Computational modelling of the 
substrate translocation path further supports the involvement of the distant loop in the transport process (Stolzenberg, 2012) and demonstrates that upon transition from the OFS to the IFS, the symmetry of the trimer can deteriorate with asymmetry arising in the transport domains of the intermediate states.

Asymmetric structures with individual protomers being in different conformational states have also been observed for AcrB, a trimeric multidrug efflux transporter in E. coli driven by 'proton motive force' (Murakami et al., 2006; Nakashami et al., 2013) and for the osmotically regulated homotrimer BetP responsible for betaine and sodium symport in Corynebacterium glutamicum (Perez et al., 2012). Similarly to sodium-coupled neurotransmitter transporters (Krishnamoorthy et al., 2009; Focke et al., 2013), BetP possesses protomers with a conserved LeuT-like fold with two inverted-topology structural repeats (Yamashita et al., 2005) and in agreement with an AA mechanism proposed for the monomeric sodium-dependent amino acid symporter LeuT (Krishnamoorthy et al., 2009), betaine translocation is thought to be mediated by the combination of rigid-body movements and individual flexing of symmetry-related helices (Perez et al., 2012).

The captured intermediate states associated with symmetry-breaking in homooligomeric transporters uncover previously unknown mechanistic details of the corresponding transport process. In Glt $\mathrm{Ph}-\mathrm{V} 198 \mathrm{CA} 380 \mathrm{C}_{\mathrm{Hg}}$, the movement of the TM helices results in widening of a crevice between the transport and trimerisation domains and formation of an amphipathic cavity at the domain interface with a possible role in substrate- and sodium-gated permeability of glutamate transporters to anions (Verdon and Boudker, 2012). In AcrB, the identified intermediate state corresponds to a conformation between the substrate-bound state and a state immediately after the extrusion of the substrates, serving a basis for the proposed three-step functionally rotating ordered export mechanism (Murakami et al., 2006). Finally, the captured intermediate conformation 
characterized with a partly unfolded region in one of the TM helices in BetP is thought to play a role in the transient coordination of $\mathrm{Na}^{+}$during AA (Perez et al., 2012).

Last but not least, an interesting form of asymmetry is encountered in EmrE, a multidrug efflux transporter from E. coli. The structure and topology of the homodimeric carrier protein remained controversial (Ninio et al., 2004; McHaourab et al., 2008; Steiner-Mordoch et al., 2008; Korkhov et al., 2009; Henzler-Wildman, 2012) until a joint NMR and single-molecule FRET investigation has recently revealed an asymmetric antiparallel arrangement with inward- and outward-facing subunits related by a pseudo-twofold symmetry axis parallel to the membrane plane (Morrison et al., 2012). Furthermore, solid state NMR and cryo-EM have demonstrated asymmetry at the ligand-binding pocket (Lehner et al., 2008), whereas spin labelling and EPR have revealed asymmetry in the TM helices (Amadi et al., 2010). NMR experiments have also shown evidence of a global exchange process occurring on the ms time scale interconverting between the two oppositely oriented states of the homodimer, which together with the different water accessibility of the two monomers confirmed the single-site AA model proposed earlier based on cryo-EM data (Fleishman et al., 2006).

In conclusion, compared with channels, transporters have more complex domain organization and a larger number of distinct functional states. Shuttling of substrates between the two sides of the lipid bilayer involves multiple isomerisation steps and requires higher energies of activation. While for primary transporters such as ABC-carriers the perturbing signal is the substrate (exporters) or the substrate-binding protein (importers), for secondary transporters it appears to be the ion (co-substrate) that also supplies the electrochemical driving force of the transport. In both cases, the perturbation elicits asymmetric conformational transitions enabling an AA of the substrate binding site to the two sides of the membrane (Fig. 4D). 


\section{Conclusions}

The previous chapter overviewed several examples of signalling proteins with symmetric oligomeric structures which become transiently less symmetric when perturbed by their signals. This is a rather monotonous list of observations of asymmetric structural changes because several relevant studies are restricted to the structural findings answering the simple question of phenomenology: what? Recent biophysical methods can elucidate how do these structural changes take place? Nevertheless, it is difficult to establish causal correlations between asymmetric perturbations and the function of a signalling protein. One of the strongest correlations is the essential role of asymmetric dimer formation in tyrosine kinase activation. Such correlations lead to the most difficult question: Why do structural and functional changes happen, what is the driving force? Speculative answers can be based on thermodynamic considerations.

According to the universal definition of symmetry, if signalling proteins are symmetric, their functional transitions can be associated with signal-elicited transient asymmetric perturbations. Sophisticated biophysical methods have recently revealed more and more such transient asymmetries. Asymmetry appears to be functionally distinctive such as the kinase versus phosphatase activities of sensor histidine kinases (Fig. 2). Transient asymmetries might have remained undetectable for these kinases with the methods applied. Further, a major thermodynamic component of the driving force of subsequent phosphorylation can mask slight asymmetric perturbations. However, transient structural asymmetries seem to be associated with functional changes in most cases.

It is tempting to draw some further speculative conclusions from the overview of symmetry of signalling proteins. The evolutionary diversification of signalling has been associated with protein oligomerization, therefore with symmetry. However, evolution "cannot afford to develop too stable" symmetric signalling oligomers because they would lose the ability for rapid functional 
and slower adaptive changes. Slight differences in the free energies of stable symmetric versus transient asymmetric states assure rapid and reversible signalling.

Symmetry breaking and asymmetric perturbations can be interpreted as transient decreases in symmetry. Symmetry mismatch can also trigger functional transitions (Goodsell and Olson, 2000). Tiny physical (electric or mechanic) effects on various 'hot spots' of proteins are sufficient to elicit asymmetric perturbations and signalling events. Alternatively, chemical signals such as ligands can bind to one of identical regulatory sites with degenerate (identical) energy levels. These multiple asymmetric perturbations can result in entropic gains. Ligand saturation at all sites points towards symmetry restoration and lead to desensitization and termination of signalling.

This review has focussed on rapid and reversible noncovalent interactions for symmetric signalling proteins. Even if subsequent covalent reactions counteract reversibility, the triggering roles of asymmetric perturbations seem to be present in a broad range of communicating networks from signalling proteins up to whole organisms.

\section{Acknowledgment}

The contribution of OT was supported by the Hungarian Research Fund (OTKA) K 109035. 


\section{References}

Abrahams, J.P., Ban, N., 2003. X-ray crystallographic structure determination of large asymmetric macromolecular assemblies. Methods in Enzymology 374, 163-188.

Adak, S., Yang, K.S., Macdonald-Obermann, J., Pike, L.J., 2011. The membrane-proximal intracellular domain of the epidermal growth factor receptor underlies negative cooperativity in ligand binding. J. Biol. Chem. 286, 45146-45155.

Aittoniemi, J., de Wet, H., Ashcroft, F.M., Sansom, M.S.P., 2010. Asymmetric switching in a homodimeric ABC transporter: a simulation study. PLoS Comput. Biol. 6, e1000762.

Akiyama, S., Fujisawa, T., Ishimori, K., Morishima, I., Aono, S., 2004. Activation mechanisms of transcriptional regulator CooA revealed by small-angle X-ray scattering. J. Mol. Biol. 341, 651-68.

Albizu, L., Cottet, M, Kralikova, M., Stoev, S., Seyer, R., Brabet, I., Roux, T., Bazin, H., Bourrier, E., Lamarque, L., Breton, C., Rives, M.-L., Newman, A., Javitch, J., Trinquet, E., Manning, M., Pin, J.-P., Mouillac, B., Durroux, T., 2010. Time-resolved FRET between GPCR ligands reveals oligomers in native tissues. Nat. Chem. Biol. 6, 587-594.

Alvarado, D., Klein, D.E., Lemmon, M.A., 2010. Structural basis for negative cooperativity in growth factor binding to an EGF receptor. Cell 142, 568-579.

Amadi, S. T., Koteiche, H. A., Mishra, S., McHaourab, H. S., 2010. Structure, dynamics, and substrateinduced conformational changes of the multidrug transporter EmrE in liposomes. J. Biol. Chem. 285, 26710-26718.

André, I., Strauss, C.E.M., Kaplan, D.B., Bradley, P., Baker, D., 2008. Emergence of symmetry in homooligomeric biological assemblies. Proc. Natl. Acad. Sci. U.S.A. 105, 16148-16152.

Arkhipov, A., Shan, Y., Das, R., Endres, N.F., Eastwood, M.P., Wemmer, D.E., Kuriyan, J., Shaw, D.E., 2013. Architecture and membrane interactions of the EGF receptor. Cell 152, 557-569.

Amadi, S.T., Koteiche, H.A., Mishra, S., Mchaourab, H.S., 2010. Structure, dynamics, and substrate-induced conformational changes of the multidrug transporter EmrE in liposomes. J. Biol. Chem. 285, 2671026718 .

Baconguis, I., Gouaux, E., 2012. Structural plasticity and dynamic selectivity of acid-sensing ion channelspider toxin complexes. Nature 489, 400-406.

Bae, J.H., Boggon, T.J., Tomé, F., Mandiyan, V., Lax, I., Schlessinger, J., 2010. Asymmetric receptor contact is required for tyrosine autophosphorylation of fibroblast growth factor receptor in living cells. Proc. Natl. Acad. Sci. U.S.A. 107, 2866-2871.

Berardi, M.J., Shih, W.M., Harrison, S.C., Chou, J.J., 2011. Mitochondrial uncoupling protein 2 structure determined by NMR molecular fragment searching. Nature 476, 109-113.

Berliner, L.J., Eaton, S.S., Eaton, G.R., 2000. Distance Measurements in Biological Systems by EPR. Kluwer Academic/Plenum Publishers Inc., New York. 
Bich, C., Zenobi, R., 2009. Mass spectrometry of large complexes. Curr. Opin. Struct. Biol. 19, 632-9.

Biemans-Oldehinkel, E., Doeven, M.K., Poolman, B., 2006. ABC transporter architecture and regulatory roles of accessory domains. FEBS Lett. 580, 1023-1035.

Birkner, J.P., Poolman, B., Kocer, A., 2012. Hydrophobic gating of mechanosensitive channel of a large conductance evidenced by single-subunit resolution. Proc. Natl. Acad. Sci. U.S.A. 109, 12944-12949.

Biskup, C., Kusch, J., Schulz, E., Nache, V., Schwede, F., Lehmann, F., Hagen, V., Benndorf, K., 2007. Relating ligand binding to activation gating in CNGA2 channels. Nature 446, 440-443.

Blundell, T.L., Srinivasan, N., 1996. Symmetry, stability, and dynamics of multidomain and multicomponent protein systems. Proc. Natl. Acad. Sci. U. S. A. 93, 14243-14248.

Boehr, D.D., Nussinov, R., Wright, P.E., 2009. The role of dynamic conformational ensembles in biomolecular recognition. Nat. Chem. Biol. 5, 789-796.

Böhme, I., Beck-Sickinger, A.G., 2009. Illuminating the life of GPCRs. Cell Commun. Signal. 7, 16.

Bolbach, G., 2005. Matrix-assisted laser desorption/ionization analysis of non-covalent complexes: fundamentals and applications. Curr. Pharm. Des. 11, 2535-2557.

Bondarenko, V., Mowrey, D.D., Tillman, T.S., Seyoum, E., Xu, Y., Tang, P., 2014. NMR structures of the human $\alpha 7 \mathrm{nAChR}$ transmembrane domain and associated anesthetic binding sites. Biochim. Biophys. Acta, doi.org/10.1016/j.bbamem.2013.12.018.

Borbat, P.P., Costa-Filho, A.J., Earle, K.A., Moscicki, J.K., Freed, J.H., 2001. Electron spin resonance in studies of membranes and proteins. Science 291, 266-269.

Boudker, O. Verdon, G., 2010. Structural perspectives on secondary active transporters. Trends in Pharm. Sci. 31, 418-426.

Boudker, O., Ryan, R.M., Yernool, D., Shimamoto, K., Gouaux, E., 2007. Coupling substrate and ion binding to extracellular gate of a sodium-dependent aspartate transporter. Nature 445, 387-393.

Broom, A., Doxey, A.C., Lobsanov, Y.D., Berthin, L.G., Rose, D.R., Howell, P.L., McConkey, B.J., Meiering, E.M., 2012. Modular evolution and the origins of symmetry: Reconstruction of a three-fold symmetric globular protein. Structure 20, 161-171.

Brown, J.H., 2006. Breaking symmetry in protein dimers: designs and functions. Protein Sci. 15, 1-13.

Cady, S.D., Wang, J., Wu, Y., DeGrado, W.F., Hong, M., 2011. Specific binding of adamantane drugs and direction of their polar amines in the pore of the influenza M2 transmembrane domain in lipid bilayers and dodecylphosphocholine micelles determined by NMR spectroscopy. J. Am. Chem. Soc. 133, 4274-4284.

Caffrey, M., Li, D., Dukkipati, A., 2012. Membrane protein structure determination using crystallography and lipidic mesophases: recent advances and successes. Biochemistry S1, 6266-6288.

Campbell, J.D., Sansom, M.S.P., 2005. Nucleotide binding to the homodimeric MJ0796 protein: a computational study of a prokaryotic ABC transporter NBD dimer. FEBS Lett. 579, 4193-4199.

Cavanagh, J., Fairbrother, W. J., Palmer, A. G., Skelton, N. J., Rance, M., 2006. Protein NMR Spectroscopy: Principles and Practice, Academic Press. 
Cerritelli, M.E., Trus, B.L., Smith, C.S., Cheng, N., Conway, J.F., Steven, A.C., 2003. A second symmetry mismatch at the portal vertex of bacteriophage T7: 8-fold symmetry in the procapsid core. J. Mol. Biol. $327,1-6$.

Changeux, J.P., Devillers-Thiéry, A., Chemouilli, P., 1984. Acetylcholine receptor: an allosteric protein. Science $225,1335-1345$.

Charalambous, K., Booth, P.J., Woscholski, R., Seddon, J.M., Templer, R.H., Law, R.V., Barter, L.M.C., Ces, O., 2012. Engineering de novo membrane-mediated protein-protein communication networks. J. Am. Chem. Soc. 134, 5746-5749.

Chen, J., 2013. Molecular mechanism of the Escherichia coli maltose transporter. Curr. Op. Struct. Biol. 23, 492-498.

Chen, T.-Y., Takeuchi, H., Kurahashi, T., 2006. Odorant inhibition of the olfactory cyclic nucleotide-gated channel with a native molecular assembly. J. Gen. Physiol. 128, 365-371.

Cheung, J., Hendrickson, W.A., 2008. Crystal structures of C4-dicarboxylate ligand complexes with sensor domains of histidine kinases DcuS and DctB. J. Biol. Chem. 283, 30256-30265.

Cheung, J., Hendrickson, W.A., 2009. Structural analysis of ligand stimulation of the histidine kinase NarX. Structure 17, 190-201.

Cohen, R.O., Shen, G., Golbeck, J.H., Xu, W., Chitnis, P.R., Valieva, A.I., van der Est, A., Pushkar, Y., Stehlik, D., 2004. Evidence for asymmetric electron transfer in cyanobacterial photosystem I: analysis of amethionine-to-leucine mutation of the ligand to the primary electron acceptor. Biochemistry 43, 4741-4754.

Collier, T.S., Diraviyam, K., Monsey, J., Shen, W., Sept, D., Bose, R., 2013. Carboxyl group footprinting mass spectrometry and molecular dynamics identify key interactions int he HER2-HER3 receptor tyrosine kinase interface. J. Biol. Chem. 288, 25254-25264.

Compton, E.L.R., Taylor, E.M., Mindell, J.A., 2010. The 3-4 loop of an archaeal glutamate transporter homolog experiences ligand-induced structural changes and is essential for transport. Proc. Natl. Acad. Sci. U. S. A. $107,12840-12845$.

Cong, Y., Schröder, G.F., Meyer, A.S., Jakana, J., Ma, B., Dougherty, M.T., Schmid, M.F., Reissmann, S., Levitt, M., Ludtke, S.L., Frydman, J., Chiu, W., 2012. Symmetry-free cryo-EM structures of the chaperonin TRiC along its ATPase-driven conformational cycle. The EMBO J. 31, 720-730.

Cristóvao, M., Sisamakis, E., Hingorani, M.M., Marx, A.D., Jung, C.P., Rothwell, P.J., Seidel, C.A.M., Friedhoff, P., 2012. Single-molecule multiparameter fluorescence spectroscopy reveals directional MutS binding to mismatched bases in DNA. Nucleic Acid Res. 40, 5448-5464.

Damian, M., Martin, A., Mesnier, D., Pin, J.-P., Banères, J.-L., 2006. Asymmetric conformational changes in a GPCR dimer controlled by G-proteins. EMBO J. 25, 5693-5702.

Damian, M., Mary, S., Martin, A., Pin, J.P., Banéres, J.L., 2008. G protein activation by the leukotriene $\mathrm{B}_{4}$ receptor dimer. J. Biol. Chem. 283, 21084-21092. 
Davidson, A.L., Maloney, P.C., 2007. ABC transporters: how small machines do a big job. Trends Microbiol. Sci. 15, 448-455.

Dayhoff, J.E., Shoemaker, B.A., Bryant, S.H., Panchenko, A.R., 2010. Evolution of protein binding modes in homooligomers. J. Mol. Biol. 395, 860-870.

Doherty, T., Su, Y., Hong, M., 2010. High-resolution orientation and depth of insertion of the voltagesensing S4 helix of a potassium channel in lipid bilayers. J. Mol. Biol. 401, 642-652.

Dyachenko, A., Gruber, R., Shimon, L., Horovitz, A., Sharon, M., 2013. Allosteric mechanisms can be distinguished using structural mass spectrometry. Proc. Natl. Acad. Sci. U. S. A. 110, 7235-7239.

Endres, N.F., Das, R., Smith, A.W., Arkhipov, A., Kovacs, E., Huang, Y., Pelton, J.G., Shan, Y., Shaw, D.E., Wemmer, D.E., Groves, J.T., Kuriyan, J., 2013. Conformational coupling across the plasma membrane in activation of the EGF receptor. Cell 152, 543-556.

Erkens, G.B., Hänelt, I., Goudsmits, J.M.H., Slotboom, D.J., van Oijen, A.M., 2013. Unsynchronised subunit motion in single trimeric sodium-coupled aspartate transporters. Nature 502, 119-123.

Fabiola, F., Korostelev, A., Chapman, M.S., 2006. Bias in cross-validated free R factors: mitigation of the effects of non-crystallographic symmetry. Acra Crystallographica D62, 227-238.

Falces, J., Arregi, I., Konarev, P.V., Urbaneja, M. A., Svergun, D.I., Taneva, S.G., Bañuelos, S., 2010. Recognition of nucleoplasmin by its nuclear transport receptor importin $\alpha / \beta$ : insights into a complete import complex. Biochemistry 49, 9756-9769.

Falkner, B., Schröder, G.F., 2013. Cross-validation in cryo-EM-based structural modeling. Proc. Natl. Acad. Sci. U.S.A. 110, 89-30-8935.

Farrow, N.A., Muhandiram, R., Singer, A.U., Pascal, S.M., Kay, C.M., Gish, G., Shoelson, S.E., Pawson, T., Forman-Kay, J.D., Kay, L.E., 1994. Backbone dynamics of a free and phosphopeptide-complexed Src homology 2 domain studied by 15N NMR relaxation. Biochemistry 33, 5984-6003.

Fei, X., Yang, D., LaRonde-LeBlanc, N., Lorimer, G.H., 2013. Crystal structure of a GroEL-ADP complex in the relaxed allosteric state at 2.7 Å resolution. Proc. Natl. Acad. Sci. U.S.A. E2958-E2966.

Feng, D., Kim, T., Özkan, E., Light, M., Torkin, R., Teng, K.K., Hempstead, B.L., Garcia, K.C., 2010. Molecular and structural insight in proNGF engagement of p75NTR and sortilin. J. Mol. Biol. 396, 967-984.

Fleishman, S.J., Harrington, S.E., Enosh, A., Halperin, D., Tate, C.G., Ben-Tal, N., 2006. Quasi-symmetry in the cryo-EM structure of EmrE provides the key to modeling its transmembrane domain. J. Mol. Biol. $364,54-67$.

Focke, P.J., Moenne-Loccoz, P., Larsson, H.P., 2011. Opposite movement of the external gate of a glutamate transporter homolog upon binding cotransported sodium compared with substrate. J. Neurosci. 31, $6255-6262$.

Focke, P.J., Valiyaveetil, F.I., 2010. Studies of ion channels using expressed protein ligation. Curr. Opin. Chem. Biol. 14, 797-802. 
Focke, P.J., Wang, X., Larsson, H.P., 2013. Neurotransmitter transporters: structure meets function. Structure 21, 694-705.

Forrest, L.R., Zhang, Y.W., Jacobs, M.T., Gesmonde, J., Xie, L., Honig, B.H., Rudnick, G., 2008. Mechanism for alternating access in neurotransmitter transporters. Proc. Natl. Acad. Sci. U.S.A. 105, 10338-10343.

Gaponenko, V., Altieri, A.S., Li, J., Byrd, R.A., 2002. Breaking symmetry in the structure determination of (large) symmetric protein dimers. J. Biomol. NMR 24, 143-148.

García-Bellido, A., 1996. Symmetries throughout organic evolution. Proc. Natl. Acad. Sci. U.S.A. 93, 14229-14232.

Gardner, K.H., Kay, L.E., 1998. The use of 2H, 13C, 15N multidimensional NMR to study the structure and dynamics of proteins. Annu. Rev. Biophys. Biomol. Struct. 27, 357-406.

Gautier, A., Mott, H.R., Bostock, M.J., Kirkpatrick, J.P., Nietlispach, D., 2010. Structure determination of the seven-helix transmembrane receptor sensory rhodopsin II by solution NMR spectroscopy. Nat. Struct. Mol. Biol. 17, 768-774.

Geng, Y., Xiong, D., Mosyak, L., Malito, D.L., Kniazeff, Chen, Y., Burmakina, S., Quick, M., Bush, M., Javitch, J.A., Pin, J.P., Fan, Q.R., 2012. Structure and functional interaction of the extracellular domain of human $\mathrm{GABA}_{B}$ receptor GBR2. Nat. Neurosci. 15, 970-978.

George, A.M., Jones, P.M., 2012. Perspectives ont he structure-function of ABC transporters: The Switch and Costant Contact models. Prog. Biophys. \& Mol. Biol. 109, 95-107.

George, A.M., Jones, P.M., 2013. An asymmetric post-hydrolysis state of the ABC transporter ATPase dimer. PLoS One 8, e59854.

Georgieva, E.R., Roy, A.S., Grigoryants, V.M., Borbat, P.P., Earle, K.A., Scholes, C.P., Freed, J.H., 2012. Effect of freezing conditions on distances and their distributions derived from Double Electron Electron Resonance (DEER): a study of doubly-spin-labeled T4 lysozyme. J. Magn. Reson. 216, 6977.

Gillette, T.G., Kumar, B., Thompson, D., Slaughter, C.A., DeMartino, G.N., 2008. Differential roles of the $\mathrm{COOH}$ termini of AAA subunits of PA700 (19S regulator) in asymmetric assembly and activation of the 26S proteasome. J. Biol. Chem. 283, 31813-31822.

Godoy-Ruiz, R., Krejcirikova, A., Gallagher, D. T., Tugarinov, V., 2011. Solution NMR evidence for symmetry in functionally or crystallographically asymmetric homodimers. J. Am. Chem. Soc. 133,19578-19582.

Goldschen-Ohm, M.P., Capes, D.L., Oelstrom, K.M., Chandra, B., 2013. Multiple pore conformations driven by asynchronous movements of voltage sensors in a eukaryotic sodium channel. Nat. Commun. 4 , 1350.

Gong, S., Worth, C.L., Bickerton, R.J., Lee, S., Tanramluk, D., Blundell, T.L., 2009. Structural and functional restraints in the evolution of protein families and superfamilies. Biochem. Soc. Trans. 37, 727-733. 
Gong, Y., Cao, P., Yu, H.J., Jiang, T., 2008. Crystal structure of the neurotrophin-3 and p $75^{\mathrm{NTR}}$ symmetrical complex. Nature 454, 789-793.

Gonzalez-Gutierrez, G., Lukk, T., Agarwal, V., Papke, D., Nair, S.K., Grosman, C., 2012. Mutations that stabilize the open state of the Erwinia chrisanthemi ligand-gated ion channel fail to change the conformation of the pore domain in crystals. Proc. Natl. Acad. Sci. U.S.A. 109, 6331-6336.

Goodsell, D.S., Olson, A.J., 2000. Structural symmetry and protein function. Annu. Rev. Biophys. Biomol. Struct. 29, 105-153.

Goudet, C., Kniazeff, J., Hlavackova, V., Malhaire, F., Maurel, D., Acher, F., Blahos, J., Prezeau, L., Pin, J.P, 2005. Asymmetric functioning of dimeric metabotropic glutamate receptors disclosed by positive allosteric modulators. J. Biol. Chem. 280, 24380-24385.

Graewert, M.A., Svergun, D.I., 2013. Impact and progress in small and wide angle X-ray scattering (SAXS and WAXS). Current Op. in Struct. Biol. 23, 748-754.

Grewer, C., Balani, P., Weidenfeller, C., Bartusel, T., Tao, Z., Rauen, T., 2005. Individual subunits of the glutamate transporter EAAC1 homotrimer function independently of each other. Biochemistry 44, 11913-11923.

Groeneveld, M., Slotboom, D.-J., 2007. Rigidity of the subunit interfaces of the trimeric glutamate transporter GltT during translocation. J. Mol. Biol. 372, 565-570.

Gryk, M.R., Finucane, M.D., Zheng, Z., Jardetzky, O., 1995. Solution dynamics of the trp repressor: a study of amide proton exchange by T1 relaxation. J. Mol. Biol. 246, 618-627.

Gutberlet, T., Heinemann, U., Steiner, M., 2001. Protein crystallography with neutrons - status and perspectives. Acta Crystallogr. D. Biol. Crystallogr. 57, 349-354.

Gyimesi, G., Ramachandran, S., Kota, P., Dokholyan, N.V, Sarkadi, B., Hegedus, T., 2011. ATP hydrolysis at one of the two sites in $\mathrm{ABC}$ transporters initiates transport related conformational transitions. Biochim. Biophys. Acta 1808, 2954-2964.

Hafenstein, S., Palermo, L.M., Kostyuchenko, V.A., Xiao, C., Morais, M.C., Nelson, C.D.S., Bowman, V.D., Battisti, A.J., Chipman, P.R., Parrish, C.R., Rossmann, M.G., 2007. Asymmetric binding of transferrin receptor to parvovirus capsids. Proc. Natl. Acad. Sci. U.S.A. 104, 6585-6589.

Han, Y., Moreira, I.S., Urizar, E., Weinstein, H., Javitch, J.A., 2009. Allosteric communication between protomers of dopamine class A GPCR dimmers modulates activation. Nat. Chem. Biol. 5, 688-695.

He, X.L., Garcia, C., 2004. Structure of nerve growth factor complexed with the shared neurotrophin receptor $\mathrm{p} 75$. Science $304,870-875$.

Henzler-Wildman, K.A., 2012. Analyzing conformational changes in the transport cycle of EmrE. Current Opinion Struct. Biol. 22, 38-43.

Hiller, S., Garces, R.G., Malia, T.J., Orekhov, V.Y., Colombini, M., Wagner, G., 2008. Solution structure of the integral human membrane protein VDAC-1 in detergent micelles. Science 321, 1206-1210. 
Hlavackova, V., Goudet, C., Kniazeff, J., Zikova, A., Maurel, D., Vol, C., Trojanova, J., Prézeau, L., Pin, J.P., Blahos, J., 2005. Evidence for a single heptahelical domain being turned on upon activation of a dimeric GPCR. The EMBO J. 24, 499-509.

Hollenstein, K., Dawson, R.J.P., Locher, K.P., 2007. Structure and mechanism of ABC transporter proteins. Curr. Opin. Struct. Biol. 17, 412-418.

Holsbeeks, I., Lagatie, O., Van Nuland, A., Van de Velde, S., Thevelein, J.M., 2004. The eukaryotic plasma membrane as a nutrient-sensing device. Trends Biochem. Sci. 29, 556-564.

Houde, D., Demarest, S.J., 2011. Fine details of IGF-1R activation, inhibition, and asymmetry determined by associated hydrogen /deuterium-exchange and peptide mass mapping. Structure 19, 890-900.

Hovius, R., Vallotton, P., Wohland, T., Vogel, H., 2000. Fluorescence techniques: shedding light on ligandreceptor interactions. Trends Pharm. Sci. 21, 266-273.

Hubbell, W.L., López, C.J., Altenbach, C., Yang, Z., 2013. Technological advances in site-directed spin labeling of proteins. Curr. Opin. Struct. Biol. 23, 725-733.

Hvorup, R.N., Goetz, B.A., Niederer, M., Hollenstein, K., Perozo, E., Locher, K.P., 2007. Asymmetry in the structure of the ABC transporter-binding protein complex BtuCD-BtuF. Science 317, 1387-1390.

Inobe, T., Takahashi, K., Maki, K., Enoki, S., Kamagata, K., Kadooka, A., Arai, M., Kuwajima, K., 2008. Asymmetry of the GroEL-GroES complex under physiological conditions as revealed by small-angle x-ray scattering. Biophys. J. 94, 1392-1402.

Isaac, B., Gallagher, G.J., Balazs, Y.S., Thompson, L.K., 2002. Site-directed rotational resonance solid-state NMR distance measurements probe structure and mechanism in the transmembrane domain of the serine bacterial chemoreceptor. Biochemistry 41, 3025-3036.

Jardetzky, O., 1996. Protein dynamics and conformational transitions in allosteric proteins. Progr. Biophys. \& Mol. Biol. 65, 171-219.

Jiang, X., Dias, J.A., He, X., 2014. Structural biology of glycoprotein hormones and their receptors: Insights to signaling. Mol. Cellular Endocrinology 382, 424-451.

Johs, A., Hammel, M., Waldner, I., May, R.P., Laggner, P., Prassl, R., 2006. Modular structure of solubilized human apolipoprotein B-100. Low resolution model revealed by small angle neutron scattering. J. Biol. Chem. 281, 19732-19739.

Joo, C., Fareh, M., Kim, V.N., 2013. Bringing single-molecule spectroscopy to macromolecular protein complexes. Trends Biochem. Sci. 38, 30-37.

Jura, N., Endres, N.F., Engel, K., Deindl, S., Das, R., Lamers, M.H., Wemmer, D.E., Zhang, X., Kuriyan, J., 2009. Mechanism for activation of the EGF receptor catalytic domain by the juxtamembrane segment. Cell 137, 1293-1307.

Jurneczko, E., Cruickshank, F., Porrini, M., Nikolova, P., Campuzano, I.D.G., Morris, M., Barran, P.E., 2012. Intrinsic disorder in proteins: a challenge for (un)structural biology met by ion mobility-mass spectrometry. Biochem. Soc. Trans. 40, 1021-1026. 
Kancha, R.K., Bubnoff, N., Duyster, J., 2013. Asymmetric kinase dimer formation is crucial for the activation of oncogenic EGFRvIII but not for ERBB3 phosphorylation. Cell Commun. Signaling 11, 39.

Karlin, A., 1967. On the application of 'a plausible model' of allosteric proteins to the receptor for acetylcholine. J. Theor. Biol. 16, 306-320.

Kasai, R. S., Kusumi, A., 2014. Single-molecule imaging revealed dynamic GPCR dimerization. Curr. Opin. Struct. Biol. 27, 78-86.

Kirshenbaum, N., Michaelevski, I., Sharon, M., 2010. Analyzing large protein complexes by structural mass spectrometry. J. Visualized Experiments 40, e1954.

Kleckner, I.R., Foster, M.P., 2011. An introduction to NMR-based approaches for measuring protein dynamics. Biochim. Biophys. Acta 1814, 942-968.

Koch, H.P., Hubbard, J.M., Larsson, H.P., 2007. Voltage-independent sodium-binding events reported by the 4B-4C loop in the human glutamate transporter excitatory amino acid transporter 3. J. Biol. Chem. $282,24547-24553$.

Koch, H.P., Larsson, H.P., 2005. Small-scale molecular motions accomplish glutamate uptake in human glutamate transporters. J. Neurosci. 25, 1730-1736.

Kojić-Prodić, B., Štefanić, Z., 2010. Symmetry versus asymmetry in the molecules of life: homomeric protein assemblies. Symmetry 2, 884-906.

Korkhov, V.M., Mireku, S. a, Hvorup, R.N., Locher, K.P., 2012a. Asymmetric states of vitamin B $_{12}$ transporter BtuCD are not discriminated by its cognate substrate binding protein BtuF. FEBS Lett. 586, 972-976.

Korkhov, V.M., Mireku, S.A., Locher, K.P., 2012b. Structure of AMP-PNP-bound vitamin B12 transporter BtuCD-F. Nature 490, 367-372.

Korkhov, V.M., Tate, C.G., 2009. An emerging consensus for the structure of EmrE. Acta Crystallogr. D. Biol. Crystallogr. 65, 186-192.

Koshland, D.E., Némethy, G., Filmer, D., 1966. Comparison of experimental binding data and theoretical models in proteins containing subunits. Biochemistry 5, 365-385.

Kriel, J., Haesendonckx, S., Rubio-Texeira, M., Van Zeebroeck, G., Thevelein, J.M., 2011. From transporter to transceptor: signaling from transporters provokes re-evaluation of complex trafficking and regulatory controls. BioEssays 33, 870-879.

Krishnamurthy, H., Gouaux, E., 2012. X-ray structures of LeuT in substrate-free outward-open and apo inward-open states. Nature 481, 469-474.

Krishnamurthy, H., Piscitelli, C.L., Gouaux, E., 2009. Unlocking the molecular secrets of sodium-coupled transporters. Nature 459, 347-355.

Kunishima, N., Shimida, Y., Tsuji, Y., Yamamoto, M., Kumasaka, T., Nakanishi, S., Jingami, H., Morikawa, K., 2000. Structural basis of glutamate recognition by a dimeric metabotropic glutamate receptor. Nature 407, 971-977. 
Kuriyan, J., Eisenberg, D., 2007. The origin of protein interactions and allostery in colocalization. Nature 450, 983-990.

Kusch, J., Thon, S., Schulz, E., Biskup, C., Nache, V., Zimmer, T., Seifert, R., Schwede, F., Benndorf, K., 2012. How subunits cooperate in cAMP-induced activation of homotetrameric HCN2 channels. Nat. Chem. Biol. 8, 162-169.

Lakshmi, K. V, Brudvig, G.W., 2001. Pulsed electron paramagnetic resonance methods for macromolecular structure determination. Curr. Opin. Struct. Biol. 11, 523-531.

Lau, W.C.Y., Rubinstein, J.L., 2012. Subnanometre-resolution structure of the intact Thermus thermophilus H+-driven ATP synthase. Nature 481, 214-218.

Leary, G.P., Stone, E.F., Holley, D.C., Kavanaugh, M.P., 2007. The glutamate and chloride permeation pathways are colocalized in individual neuronal glutamate transporter subunits. J. Neurosci. 27, 29382942.

Lee, G.M., Craik, C.S., 2009. Trapping moving targets with small molecules. Science 324, 213-215.

Lee, J., Blaber, M., 2011. Experimental support for the evolution of symmetric protein architecture from a simple peptide motif. Proc. Natl. Acad. Sci. U.S.A. 108, 126-130.

Lehner, I., Basting, D., Meyer, B., Haase, W., Manolikas, T., Kaiser, C., Karas, M., Glaubitz, C., 2008. The key residue for substrate transport $\left(\mathrm{Glu}^{14}\right)$ in the EmrE dimer is asymmetric. J. Biol. Chem., 283, 3281-3288.

Levitt, M., 2001. The birth of computational structural biology. Nat. Struct. Biol. 8, 392-393.

Levy, E.D., Erba, E.B., Robinson, C.V., Teichmann, S.A., 2008. Assembly reflects evolution of protein complexes. Nature 453, 1262-1266.

Lewis, M., Arnot, C.J., Beeston, H., McCoy, A., Ashcroft, A.E., Gay, N.J., 2013. Cytokine Spätzle binds to the Drosophila immunoreceptor Toll with a neurotrophin-like specificity and couples receptor activation. Proc. Natl. Acad. Sci. USA 110, 20461-20466.

Liao, M., Cao, E., Julius, D., Cheng., 2013. Structure of the TRPV1 ion channel determined by electron cryo-microscopy. Nature 504, 107-112.

Liu, P., Cleveland, T.E., Bouyain, S., Byrne, P.O., Longo, P.A., Leahy, D.J., 2012a. A single ligand is sufficient to activate EGFR dimers. Proc. Natl. Acad. Sci. U.S.A. 109, 10861-10866.

Liu, J.J., Horst, R., Katritch, V., Stevens, R.C., Wüthrich, K., 2012b. Biased signaling pathways in $\beta 2-$ adrenergic receptor characterized by 19F-NMR. Science 335, 1106-1110.

Liu, W., Wacker, D., Gati, C., Han, G.W., James, D., Wang, D., Nelson, G., Weierstall, U., Katritch, V., Barty, A., Zatsepin, N.A., Li, D., Messerschmidt, M., Boutet, S., Williams, G.J., Koglin, J.E., Seibert, M.M., Wang, C., Shah, S.T.A., Basu, S., Fromme, R., Kupitz, C., Rendek, K.N., Grotjohann, I., Fromme, P., Kirian, R.A., Beyíerlein, K.R., White, T.A., Chapman, H.N., Caffrey, M., Spence, J.C.H., Stevens, R.C., Cherezov, V., 2013. Serial femtosecond crystallography of G protein-coupled receptors. Science 342, 1521-1524. 
Locher, K.P., Lee, A.T., Rees, D.C., 2002. The E. coli BtuCD structure: a framework for ABC transporter architecture and mechanism. Science 296, 1091-1098.

Lohse, M.J., Nikolaev, V.O., Hein, P., Hoffmann, C., Vilardaga, J.-P., Bünemann, M., 2008. Optical techniques to analyze real-time activation and signaling of G-protein-coupled receptors. Trends Pharm. Sci. 29, 159-165.

Lolkema, J.S., Slotboom, D.J., 2003. Classification of 29 families of secondary transport proteins into a single structural class using hydropathy profile analysis. J. Mol. Biol. 327, 901-909.

Loria, J.P., Rance, M., Palmer, A.G., 1999. A TROSY CPMG sequence for characterizing chemical exchange in large proteins. J. Biomol. NMR 15, 151-155.

Ludtke, S.J., Tran, T.P., Ngo, Q.T., Moiseenkova-Bell, V.Y., Chiu, W., Serysheva, I.I., 2011. Flexible architecture of IP3R1 by Cryo-EM. Structure 19, 1192-1199.

Macdonald-Obermann, J.L., Piwnica-Worms, D., Pike, L.J., 2012. Mechanics of EGF receptor/ErbB2 kinase activation revealed by luciferase fragment complementation imaging. Proc. Natl. Acad. Sci. U.S.A. $109,137-142$.

Maeda, S., Nakagawa, S., Sura, M., Yamashita, E., Oshima, A., Fujiyoshi, Y., Tsukihara, T., 2009. Structure of the connexin 26 gap junction channel at $3.5 \AA$ resolution. Nature 458, 597-602.

Maksay, G., 2011. Allostery in pharmacology: thermodynamics, evolution and design, Progr. Biophys. \& Mol. Biol. 106, 463-473.

Maksay, G., 2013. Asymmetric perturbation of pLGICs: action! Trends Pharm. Sci. 34, 299-300.

Mancia, F., Assur, Herman, A.G., Siegel, R., Hendrickson, W.A., 2008. Ligand sensitivity in dimeric associations of the serotonin 5HT2c receptor. EMBO reports 9, 363-369.

Matsunaga, Y., Koike, R., Ota, M., Tame, J.R.H., Kidera, A., 2012. Influence of structural symmetry on protein dynamics. PLoS ONE 7, e50011.

Matsushita, S., Nakata, H., Kubo, Y., Tateyama, M., 2010. Ligand-induced rearrangements of the GABA $A_{B}$ receptor revealed by fluorescence resonance energy transfer. J. Biol. Chem. 285, 10291-10299.

Matyskiela, M.E., Lander, G.C., Martin, A., 2013. Conformational switching of the 26S proteasome enables substrate degradation. Nature Struct. \& Mol. Biol. 20, 781-788.

Maurice, P., Daulat, A.M., Turecek, R., Ivankova-Susankova, K., Zamponi, F., Kamal, M., Clement, N., Guillaume, J.L., Bettler, B., Galés, C., Delagrange, P., Jockers, R., 2010. Molecular organization and dynamics of the melatonin $\mathrm{MT}_{1}$ receptor/RGS20/G $\mathrm{G}_{\mathrm{i}}$ protein complex reveal asymmetry of receptor dimmers for RGS and $\mathrm{G}_{\mathrm{i}}$ coupling. The EMBO J. 29, 3646-3659.

Maurice, P., Kamal, M., Jockers, R., 2011. Asymmetry of GPCR oligomers supports their functional relevance. Trends Pharm. Sci. 32, 514-520.

May, E.R., Feng, J., Brooks, C.L., 2012. Exploring the symmetry and mechanism of virus capsid maturation via an ensemble of pathways. Biophys. J. 102, 606-612.

McHaourab, H.S., Mishra, S., Koteiche, H.A., Amadi, S.H., 2008. Role of sequence bias in the topology of the multidrug transporter EmrE. Biochemistry 47, 7980-7982. 
Meirovitch, E., Shapiro, Y.E., Polimeno, A., Freed, J.H., 2010. Structural dynamics of bio-macromolecules by NMR: the slowly relaxing local structure approach. Prog. Nucl. Magn. Reson. Spectrosc. 56, 360405.

Mendel, D., Cornish, V.W., Schultz, P.G., 1995. Site-directed mutagenesis with an expanded genetic code. Annu. Rev. Biophys. Biomol. Struct. 24, 435-62.

Mi, L.Z., Lu, C., Li, Z., Nishida, N., Walz, T., Springer, T.A., 2011. Simultaneous visualization of the extracellular and cytoplasmic domains of the epidermal growth factor receptor. Nat. Struct. \& Mol. Biol. 18, 984-989.

Míguez, D.G., 2010. The role of asymmetric binding in ligand-receptor systems with 1:2 interaction ratio. Biophys. Chem. 148, 74-81.

Milne, J.L.S., Borgnia, M.J., Bartesaghi, A., Tran, E.E.H., Earl, L.A., Schauder, D.M., Lengyel, J., Pierson, J., Patwardhan, A., Subramaniam, S., 2013. Cryo-electron microscopy - a primer for the nonmicroscopist. FEBS J. 280, 28-45.

Mittal, A., Böhm, S., Grütter, M.G., Bordignon, E., Seeger, M.A, 2012. Asymmetry in the homodimeric ABC transporter MsbA recognized by a DARPin. J. Biol. Chem. 287, 20395-20406.

Mittermaier, A.K., Kay, L.E., 2009. Observing biological dynamics at atomic resolution using NMR. Trends Biochem. Sci. 34, 601-611.

Monod, J., Wyman, J., Changeux, J.P., 1965. On the nature of allosteric transitions: A plausible model. J. Mol. Biol. 12, 88-118.

Moore, J.O., Hendrickson, W.A., 2012. An asymmetry-to-symmetry switch in signal transmission by the histidine kinase receptor for TMAO. Structure 20, 729-741.

Morrison, E.A., DeKoster, G.T., Dutta, S., Vafabakhsh, R., Clarkson, M.W., Bahl, A., Kern, D., Ha, T., Henzler-Wildman, K.A, 2012. Antiparallel EmrE exports drugs by exchanging between asymmetric structures. Nature 481, 45-50.

Mowrey D., Cheng, M.H., Liu, L.T., Willenbring, D., Lu, X., Wymore, T., Xu, Y., Tang, P., 2013. Asymmetric ligand binding facilitates conformational transitions in pentameric ligand-gated ion channels. J. Am. Chem. Soc. 135, 2172-2180.

Mueller, M., Jenni, S., Ban, N., 2007. Strategies for crystallization and structure determination of very large macromolecular assemblies. Curr. Opinion Struct. Biol. 17, 572-579.

Murakami, S., Nakashima, R., Yamashita, E., Matsumoto, T., Yamaguchi, A., 2006. Crystal structures of a multidrug transporter reveal a functionally rotating mechanism. Nature 443, 173-179.

Murphy, O.J., Kovacs, F.A., Sicard, E.L., Thompson, L.K., 2001. Site-directed solid-state NMR measurement of a ligand-induced conformational change in the serine bacterial chemoreceptor. Biochemistry 40, 1358-1366.

Nakashima, R., Sakurai, K., Yamasaki, S., Hayashi, K., Nagata, C., Hoshino, K., Onodera, Y., Nishino, K., Yamaguchi, A., 2013. Structural basis for the inhibition of bacterial multidrug exporters. Nature 500, $102-106$. 
Nakagawa, T., Cheng, Y., Ramm, E., Sheng, M., Walz, T., 2005. Structure and different conformational states of native AMPA receptor complexes. Nature 433, 545-549.

Neiditsch, M.B., Federle, M.J., Pompeani, A.J., Kelly, R.C., Swem, D.L., Jeffrey, P.D., Bassler, B.L., Hughson, F.M., 2006. Ligand-induced asymmetry in histidine sensor kinase complex regulates quorum sensing. Cell 126, 1095-1108.

Ninio, S., Elbaz, Y., Schuldiner, S., 2004. The membrane topology of EmrE - a small multidrug transporter from Escherichia coli. FEBS Lett. 562, 193-196.

Nishimura, K., Kim, S., Zhang, L., Cross, T.A., 2002. The closed state of a H+ channel helical bundle combining precise orientational and distance restraints from solid state NMR. Biochemistry 41, 13170-13177.

Nowak, E., Panjikar, S., Konarev, P., Svergun, D.I., Tucker, P. A., 2006a. The structural basis of signal transduction for the response regulator PrrA from Mycobacterium tuberculosis. J. Biol. Chem. 281, 9659-9666.

Nowak, E., Panjikar, S., Morth, J.P., Jordanova, R., Svergun, D.I., Tucker, P.A., 2006b. Structural and functional aspects of the sensor histidine kinase PrrB from Mycobacterium tuberculosis. Structure 14, $275-285$.

Nys, M., Kesters, D., Ulens, C., 2013. Structural insights into Cys-loop receptor function and ligand recognition. Biochem. Pharmacol. 86, 1042-1053.

Opella, S.J., Marassi, F.M., 2004. Structure determination of membrane proteins by NMR spectroscopy. Chem. Rev. 104, 3587-3606.

Orekhov, V.Y., Ibraghimov, I. V, Billeter, M., 2001. MUNIN: a new approach to multi-dimensional NMR spectra interpretation. J. Biomol. NMR 20, 49-60.

Oshima, A., Tani, K., Toloue, M.M., Hiroaki, Smock, A., Inukai, S., Cone, A., Nicholson, B.J., Sosinsky, G.E., Fujiyoshi, Y., 2011. Asymmetric configurations and N-terminal rearrangements in connexin26 gap junction channels. J. Mol. Biol. 405, 724-735.

Payandeh, J., El-Din, T.M.G., Scheuer, T., Zheng, N., Catterall, W.A., 2012. Crystal structure of a voltagegated sodium channel in two potentially inactivated states. Nature 486, 135-139.

Payandeh, J., Scheuer, T., Zheng, N., Catterall, W.A., 2011. The crystal structure of a voltage-gated sodium channel. Nature 475, 353-358.

Pellegrini, L., Burke, D.F., von Delft, F., Mulloy, B., Blundell, T.L., 2000. Crystal structure of fibroblast growth factor receptor ectodomain bound to ligand and heparin. Nature 407, 1029-34.

Perez, C., Koshy, C., Yildiz, O., Ziegler, C., 2012. Alternating-access mechanism in conformationally asymmetric trimers of the betaine transporter BetP. Nature 490, 126-130.

Perilla, J.R., Leahy, D.J., Woolf, T.B., 2013. Molecular dynamics simulations of transitions for ECD epidermal growth factor receptor show key differences between human and drosophila forms of the receptors. Proteins 81, 1113-1126. 
Perozo, E., Cortes, D.M., Sompornpisut, P., Kloda, A, Martinac, B., 2002a. Open channel structure of MscL and the gating mechanism of mechanosensitive channels. Nature 942-948.

Perozo, E., Kloda, A, Cortes, D.M., Martinac, B., 2002b. Physical principles underlying the transduction of bilayer deformation forces during mechanosensitive channel gating. Nat. Struct. \& Mol. Biol. 9, 696703.

Pervushin, K., Riek, R., Wider, G., Wüthrich, K., 1997. Attenuated T2 relaxation by mutual cancellation of dipole-dipole coupling and chemical shift anisotropy indicates an avenue to NMR structures of very large biological macromolecules in solution. Proc. Natl. Acad. Sci. U. S. A. 94, 12366-12371.

Petoukhov, M.V., Svergun, D.I., 2007. Analysis of X-ray and neutron scattering from biomolecular solutions. $17,562-571$.

Pfoh, R., Li, A., Chakrabarti, N., Payandeh, J., Pomés, R., Pai, E.F., 2012. Structural asymmetry in the magnesium channel CorA points to sequential allosteric regulation. Proc. Natl. Acad. Sci. U.S.A. 109, 18809-18814.

Piana, S., Carloni, P., Rothlisberger, U., 2002. Drug resistance in HIV-1 protease: Flexibility-assisted mechanism of compensatory mutations. Protein Sci. 11, 2393-2402.

Popova, Y., Thayumanavan, P., Lonati, E., Agrochão, M., Thevelein, J.M., 2010. Transport and signaling through the phosphate-binding site of the yeast Pho84 phosphate transceptor. Proc. Natl. Acad. Sci. U.S. A. 107, 2890-2895.

Popovych, N., Sun, S., Ebright, R.H., Kalodimos, C.G., 2006. Dynamically driven protein allostery. Nat. Struct. \& Mol. Biol. 13, 831-838.

Popovych, N., Tzeng, S.-R., Tonelli, M., Ebright, R.H., Kalodimos, C.G., 2009. Structural basis for cAMPmediated allosteric control of the catabolite activator protein. Proc. Natl. Acad. Sci. U. S. A. 106, 6927-6932.

Prisner, T., Rohrer, M., McMillan, F., 2001. Pulsed EPR spectroscopy: biological applications. Annu. Rev. Phys. Chem. 52, 279-313.

Procko, E., O’Mara, M.L., Bennett, W.F.D., Tieleman, D.P., Gaudet, R., 2009. The mechanism of ABC transporters: general lessons from structural and functional studies of an antigenic peptide transporter. FASEB J. 23, 1287-302.

Putnam, C.D., Hammel, M., Hura, G.L., Tainer, J.A., 2007. X-ray solution scattering (SAXS) combined with crystallography and computation: defining accurate macromolecular structures, conformations and assemblies in solution. Q. Rev. Biophys. 40, 191-285.

Rambo, R.P., Tainer, J.A., 2013. Super-resolution in solution X-ray scattering and its applications to structural systems biology. Annual Rev. Biophysics 42, 415-441.

Rasmussen, S.G.F., Choi, H.J., Fung, J.J., Pardon, E., Casarosa, P., Chae, P.S., DeVree, B.T., Rosenbaum, D.M., Thian, F.S., Kobilka, T.S., Schnapp, A., Konetzki, I., Sunahara, R.K., Gellman, S.H., Pautsch, A., Steyaert, J., Weis, W.I., Kobilka, B.K., 2011a. Structure of a nanobody-stabilized active state of the $\beta(2)$ adrenoreceptor. Nature 469, 175-180. 
Rasmussen, S.G.F., DeVree, B.T., Zou, Y., Kruse, A.C., Chung, K.Y., Kobilka, T.S., Thian, F.S., Chae, P.S., Pardon, E., Calinski, D., Mathiesen, J.M., Shah, S.T.A., Lyons, J.A, Caffrey, M., Gellman, S.H., Steyaert, J., Skiniotis, G., Weis, W.I., Sunahara, R.K., Kobilka, B.K., 2011b. Crystal structure of the $\beta 2$ adrenergic receptor-Gs protein complex. Nature 477, 549-555.

Rayes, D., De Rosa, M.J., Sine, S.M., Bouzat, C., 2009. Number and locations of agonist binding sites required to activate homomeric Cys-loop receptors. J. Neurosci. 29, 6022-6032.

Reissmann, S., Joachimiak, L.A., Chen, B., Meyer, A.S., Nguyen, A., Frydman, J., 2012. A gradient of ATP affinities generates an asymmetric power stroke driving the chaperonin TRIC/CCT folding cycle. Cell reports 2, 866-877.

Reyes, N., Ginter, C., Boudker, O., 2009. Transport mechanism of a bacterial homologue of glutamate transporters. Nature 462, 880-885.

Reynolds, P.R., Mottur, G.P., Bradbeer, C., 1980. Transport of vitamin B12 in Escherichia coli. Some observations on the roles of the gene products of BtuC and TonB. J. Biol. Chem. 255, 4313-4319.

Rice, A.J., Alvarez, F.J.D., Schultz, K.M., Klug, C.S., Davidson, A.L., Pinkett, H.W., 2013. EPR spectroscopy of MolB2C2-a reveals mechanism of transport for a bacterial type II molybdate importer. J. Biol. Chem. 288, 21228-21235.

Riek, U., Scholz, R., Konarev, P., Rufer, A., Suter, M., Nazabal, A., Ringler, P., Chami, M., Müller, S.A., Neumann, D., Forstner, M., Hennig, M., Zenobi, R., Engel, A., Svergun, D., Schlattner, U., Wallimann, T., 2008. Structural properties of AMP-activated protein kinase: dimerization, molecular shape and changes upon ligand binding. J. Biol. Chem. 283, 18331-18343.

Rochel, N., Ciesielski, F., Godet, J., Moman, E., Roessle, M., Peluso-Iltis, C., Moulin, M., Haertlein, M., Callow, P., Mély, Y., Svergun, D.I., Moras, D., 2011. Common architecture of nuclear receptor heterodimers on DNA direct repeat elements with different spacings. Nat. Struct. Mol. Biol. 18, 564570.

Ross, J.B., Senear, D.F., Waxman, E., Kombo, B.B., Rusinova, E., Huang, Y.T., Laws, W.R., Hasselbacher, C.A., 1992. Spectral enhancement of proteins: biological incorporation and fluorescence characterization of 5-hydroxytryptophan in bacteriophage lambda cI repressor. Proc. Natl. Acad. Sci. U. S. A. $89,12023-12027$.

Rossmann, M. G., Morais, M. C., Leiman, P. G., Zhang, W., 2005. Combining X-ray crystallography and electron microscopy. Structure 13, 355-362.

Rovira, X., Pin, J.P., Giraldo, J., 2009. The asymmetric/symmetric activation of GPCR dimers as a possible mechanistic rationale for multiple signalling pathways. Trends Pharm. Sci. 31, 15-21.

Ruotolo, B.T., Benesch, J.L.P., Sandercock, A.M., Hyung, S.-J., Robinson, C. V, 2008. Ion mobility-mass spectrometry analysis of large protein complexes. Nat. Protoc. 3, 1139-1152.

Ruotolo, B.T., Giles, K., Campuzano, I., Sandercock, A.M., Bateman, R.H., Robinson, C. V, 2005. Evidence for macromolecular protein rings in the absence of bulk water. Science 310, 1658-1661. 
Saibil, H.R., 2000. Macromolecular structure determination by cryo-electron microscopy. Acta Crystallogr. D. Biol. Crystallogr. 56, 1215-1222.

Sanders, C.R., Landis, G.C., 1995. Reconstitution of membrane proteins into lipid-rich bilayered mixed micelles for NMR studies. Biochemistry 34, 4030-4040.

Schulz, G.E., 2009. The dominance of symmetry in the evolution of homo-oligomeric proteins. J. Mol. Biol. $395,834-843$.

Sharon, M., 2013. Structural MS pulls its weight. Science 340. 1059-1060.

Siarheyeva, A., Liu, R., Sharom, F.J., 2010. Characterization of an asymmetric occluded state of Pglycoprotein with two bound nucleotides: implications for catalysis. J. Biol. Chem. 285, 7575-7586.

Siu, F.Y., He, M., de Graaf, C., Han, G.W., Yang, D., Zhang, Z., Zhou, C., Xu, Q., Wacker, D., Joseph, J.S., Liu, W., Lau, J., Cherezov, V., Katritch, V., Wang, M.W., Stevens, R.C., 2013. Structure of the human glucagon class B G-protein-coupled receptor. Nature 499, 444-449.

Smith, S.O., Smith, C., Shekar, S., Peersen, O., Ziliox, M., Aimoto, S., 2002. Transmembrane Interactions in the Activation of the Neu Receptor Tyrosine Kinase ?. Biochemistry 41, 9321-9332.

Smock, R.G., Gierasch, L.M., 2009. Sending signals dynamically. Science 324, 198-203.

Smriti, Zou, P., McHaourab, H.S., 2009. Mapping daunorubicin-binding Sites in the ATP-binding cassette transporter MsbA using site-specific quenching by spin labels. J. Biol. Chem. 284, 13904-13913.

Sobolevsky, A.I., Rosconi, M.P., Gouaux, E., 2009. X-ray structure, symmetry and mechanism of an AMPAsubtype glutamate receptor. Nature 462, 745-756.

Sommer, M.E., Hofmann, K.P., Heck, M., 2012. Distinct loops in arrestin differentially regulate ligand binding within the GPCR opsin. Nat. Commun. 3, e995.

Sonne, J., Kandt, C., Peters, G.H., Hansen, F.Y., Jensen, M.Ø., Tieleman, D.P., 2007. Simulation of the coupling between nucleotide binding and transmembrane domains in the ATP binding cassette transporter BtuCD. Biophys. J. 92, 2727-2734.

Spurny, R. Billen, B., Howard, R.J., Brams, R., Debaveye, S., Price, K.L., Weston, D.A., Strelkov, S.V., Tytgat, J., Bertrand, S., Bertrand, D., Lummis, S.C.H., Ulens, C., 2013. J. Biol. Chem. 288, 83558364.

Spurny, R., Ramerstorfer, J., Price, K., Brams, M., Ernst, M., Nury, H., Verheij, M., Legrand, P., Bertrand, D., Bertrand, S., Dougherty, D. A., de Esch, I. J., Corringer, P. J., Sieghart, W., Lummis, S. C., Ulens, C., 2012. Pentameric ligand-gated ion channel ELIC is activated by GABA and modulated by benzodiazepines. Proc. Natl. Acad. Sci. U.S.A. 109, E3028-E3034.

Stehlik, D., Möbius, K., 1997. New EPR methods for investigating photoprocesses with paramagnetic intermediates. Annu. Rev. Phys. Chem. 48, 745-784.

Steiner-Mordoch, S., Soskine, M., Solomon, D., Rotem, D., Gold, A., Yechieli, M., Adam, Y., Schuldiner, S., 2008. Parallel topology of genetically fused EmrE homodimers. EMBO J. 27, 17-26. 
Steven, A., Trus, B.L., Booy, F,P., Cheng, N., Zlotnick, A., Caston, J.R., Conway, J.F., 1997. The making and breaking of symmetry in virus capsid assembly: glimpses of capsid biology from cryoelectron microscopy. FASEB J. 11, 733-742.

Stolzenberg, S., Khelashvili, G., Weinstein, H., 2012. Structural intermediates in a model of the substrate translocation path of the bacterial glutamate transporter homologue GltPh. J. Phys. Chem. B 116, $5372-5383$.

Stouffer, A.L., Acharya, R., Salom, D., Levine, A.S., Di Costanzo, L., Soto, C.S., Tereshko, V., Nanda, V., Stayrook, S., DeGrado, W.F., 2008. Structural basis for the function and inhibition of an influenza virus proton channel. Nature 451, 596-599.

Struts, A. V, Salgado, G.F.J., Brown, M.F., 2011a. Solid-state 2H NMR relaxation illuminates functional dynamics of retinal cofactor in membrane activation of rhodopsin. Proc. Natl. Acad. Sci. U. S. A. 108, 8263-8268.

Struts, A. V, Salgado, G.F.J., Martínez-Mayorga, K., Brown, M.F., 2011b. Retinal dynamics underlie its switch from inverse agonist to agonist during rhodopsin activation. Nat. Struct. Mol. Biol. 18, 392394.

Sugiyama, M., Kurimoto, E., Yagi, H., Mori, K., Fukunaga, T., Hirai, M., Zaccai, G., Kato, K., 2011. Kinetic asymmetry of subunit exchange of homooligomeric protein as revealed by deuterium-assisted smallangle neutron-scattering. Biophys. J. 101, 2037-2042.

Swapna, L.S., Srikeerthana, K., Srinivasan, N., 2012. Extent of structural asymmetry in homodimeric proteins: prevalence and relevance. PLoS ONE 7, e36688.

Takei, Y., Iizuka, R., Ueno, T., Funatsu, T., 2012. Single-molecule observation of protein folding in symmetric GroEL-(GroES) $)_{2}$ complexes. J. Biol. Chem. 287, 41118-41125.

Tapaneeyakorn, S., Goddard, A. D., Oates, J., Willis, C. L., Watts, A. 2011, Solution- and solid-state NMR studies of GPCRs and their ligands. Biochim. Biophys. Acta 1808, 1462-1475.

Theobald, D.L., Miller, C., 2010. Membrane transport proteins: surprises in structural sameness. Nat. Struct. Mol. Biol. 17, 2-3.

Thompson, D., 1952. On Growth and Form, Cambridge Univ. Press, Cambridge, UK.

Thompson, L.K., 2002. Solid-state NMR studies of the structure and mechanisms of proteins. Curr. Opin. Struct. Biol. 12, 661-669.

Tjandra, N., Bax, A., 1997. Direct measurement of distances and angles in biomolecules by NMR in a dilute liquid crystalline medium. Science 278, 1111-4.

Tokuriki, N., Tawfik, D.S., 2009. Protein dynamism and evolvability. Science 324, 203-207.

Traaseth, N.J., Verardi, R., Veglia, G., 2008. Asymmetric methyl group labeling as a probe of membrane protein homo-oligomers by NMR spectroscopy. J. Am. Chem. Soc. 130, 2400-2401.

Tsai, C.J., Ma, B., Nussinov, R., 1999. Folding and binding cascades: shifts in energy landscapes. Proc. Natl. Acad. Sci. U. S. A. 96, 9970-9972.

Tsien, R.Y., 1998. The green fluorescent protein. Annu. Rev. Biochem. 67, 509-544. 
Tugarinov, V., Kanelis, V., Kay, L.E., 2006. Isotope labeling strategies for the study of high-molecularweight proteins by solution NMR spectroscopy. Nat. Protoc. 1, 749-754.

Tugarinov, V., Kay, L.E., 2003. Quantitative NMR studies of high molecular weight proteins: application to domain orientation and ligand binding in the 723 residue enzyme malate synthase G. J. Mol. Biol. 327, $1121-1133$.

Tugarinov, V., Kay, L.E., Ibraghimov, I., Orekhov, V.Y., 2005. High-resolution four-dimensional 1H-13C NOE spectroscopy using methyl-TROSY, sparse data acquisition, and multidimensional decomposition. J. Am. Chem. Soc. 127, 2767-2775.

Tzeng, S.-R. and Kalodimos, C. G., 2009. Dynamic activation of an allosteric regulatory protein. Nature 462, 368-372.

Tzeng, S.-R., Kalodimos, C.G., 2013. Allosteric inhibition through suppression of transient conformational states. Nat. Chem. Biol. 9, 462-465.

Ubarretxena-Belandia, I., Stokes, D.L., 2012. Membrane protein structure determination by electron crystallography. Curr. Opin. Struct. Biol. 22, 520-528.

Unwin, N., 1995. Acetylcholine receptor channel imaged in the open state. Nature 373, 37-43.

Unwin, N., 2005. Refined structure of the nicotinic acetylcholine receptor at $4 \AA$ resolution. J. Mol. Biol. 346, 967-989.

Uysal, S., Vásquez, V., Tereshko, V., Esaki, K., Fellouse, F.A., Sidhu, S.S., Koide, S., Perozo, E., Kossiakoff, A., 2009. Crystal structure of full-length KcsA in its closed conformation. Proc. Natl. Acad. Sci.U. S. A. 106, 6644-6649.

Verdon, G., Boudker, O., 2012. Crystal structure of an asymmetric trimer of a bacterial glutamate transporter homolog. Nat. Struct. Mol. Biol. 19, 355-357.

Wall, M.E., Gallagher, S.C., Trewhella, J., 2000. Large-scale shape changes in proteins and macromolecular complexes. Annu. Rev. Phys. Chem. 51, 355-380.

Walters, K.J., Dayie, K.T., Reece, R.J., Ptashne, M., Wagner, G., 1997. Structure and mobility of the PUT3 dimer. Nat. Struct. Biol. 4, 744-750.

Weingarth, M., Baldus, M., 2013. Solid-State NMR-Based Approaches for Supramolecular Structure Elucidation. Acc. Chem. Res. 46, 2037-2046.

Williamson, P.T.F., Verhoeven, A., Miller, K.W., Meier, B.H., Watts, A., 2007. The conformation of acetylcholine at its target site in the membrane-embedded nicotinic acetylcholine receptor. Proc. Natl. Acad. Sci. U. S. A. 104, 18031-18036.

Xu, H., Staszewski, L., Tang, H., Adler, E., Zoller, M., Li, X., 2004. Different functional roles of T1R subunits in the heteromeric taste receptors. Proc. Natl. Acad. Sci. U.S.A. 101, 14258-14263.

Yamashita, A., Singh, S.K., Kawate, T., Jin, Y., Gouaux, E., 2005. Crystal structure of a bacterial homologue of $\mathrm{Na}+/ \mathrm{Cl}^{-}$-dependent neurotransmitter transporters. Nature 437, 215-223.

Yernool, D., Boudker, O., Jin, Y., Gouaux, E., 2004. Structure of a glutamate transporter homologue from Pyrococcus horikoshii. Nature 431, 811-818. 
Yung, A., Turnbull, W. B., Kalverda, A. P., Thompson, G. S., Homans, S. W., Kitov, P., Bundle, D. R., 2003. Large-scale millisecond intersubunit dynamics int he B subunit homopentamer int he toxin derived from Escherichia coli O157. J. Am. Chem. Soc. 125, 13058-13062.

Zaitseva, J., Oswald, C., Jumpertz, T., Jenewein, S., Wiedenmann, A., Holland, I.B., Schmitt, L., 2006. A structural analysis of asymmetry required for catalytic activity of an ABC-ATPase domain dimer. The EMBO J. 25, 34323443.

Zandarashvili, L., Vuzman, D., Esadze, A., Takayama, Y., Sahu, D., Levy, Y., Iwahara, J., 2012. Asymmetrical roles of zinc fingers in dynamic DNA-scanning process by the inducible transcription factor Egr-1. Proc. Natl. Acad. Sci. U. S. A. 109, E1724-E1732.

Zhang, N., Gordiyenko, Y., Joly, N., Lawton, E., Robinson, C.V., Buck, M., 2014. Subunit dynamics and nucleotide-dependent asymmetry of an $\mathrm{AAA}^{+}$transcription complex. J. Mol. Biol. 426, 71-83.

Zhang, X., Gureasko, J., Shen, K., Cole, P.A., Kuriyan, J., 2006. An allosteric mechanism for activation of the kinase domain of epidermal growth factor receptor. Cell 125, 1137-1149.

Zhang, X., Ren, W., DeCaen, P., Yan, C., Tao, X., Tang, L., Wang, J., Hasegawa, K., Kumasaka, T., He, J., Wang, J., Clapham, D.E., Yan, N., 2012. Crystal structure of an orthologue of the NaChBac voltagegated sodium channel. Nature 486, 130-134.

Zhao, G., Perilla, J.R., Yufenyuy, E.L., Meng, X., Chen, B., Ning, J., Ahn, J., Gronenborn, A.M., Schulten, K., Aiken, C., Zhang, P., 2013. Mature HIV-1 capsid structure by cryo-electron microscopy and allatom molecular dynamics. Nature 497, 643-646.

Zhou, H.X., Gilson, M.K., 2009. Theory of free energy and entropy in noncovalent binding. Chem. Rev. 109, $4092-4107$.

Zhou, Z.H., 2008. Towards atomic resolution structural determination by single-particle cryo-electron microscopy. Current Opinion Struct. Biol. 18, 218-228. 
Table 1. Comparative summary of the strengths and limitations of biophysical techniques

aiming the distinction between symmetric and asymmetric architectures.

\begin{tabular}{|c|c|c|}
\hline & STRENGTHS & LIMITATIONS \\
\hline XRC & $\begin{array}{l}\text { - atomic scale structural information } \\
\text { - large macromolecular complexes can } \\
\text { be investigated }\end{array}$ & $\begin{array}{l}\text { - } \quad \text { requirement for single crystals } \\
\text { - conformational heterogeneity and flexibility } \\
\text { are poorly tolerated } \\
\text { - limited to low energy conformations } \\
\text { - lattice forces may give rise to distortions/ } \\
\text { artefacts }\end{array}$ \\
\hline FS & $\begin{array}{l}\text { - } \\
\text { infoructural, thermodynamic and kinetic } \\
\text { - } \quad \text { high sensitivity } \\
\text { - } \quad \text { in vitro and in vivo conditions } \\
\text { - } \quad \text { single molecule details are possible }\end{array}$ & $\begin{array}{ll}\text { - } & \text { need for fluorescent label(s) } \\
\text { - } & \text { differential labelling required for FRET } \\
\text { - } & \text { residue level structural information }\end{array}$ \\
\hline $\begin{array}{l}\text { EM } \\
\text { EC }\end{array}$ & $\begin{array}{l}\text { - } \begin{array}{l}\text { information on shape and assembly } \\
\text { state of macromolecular complexes }\end{array} \\
\text { - } \quad \text { EC: high resolution } \\
\text { - } \quad \text { membrane-embedded proteins }\end{array}$ & $\begin{array}{l}\text { - negative-staining may give rise to artefacts } \\
\text { cryogenic conditions to achieve good signal- } \\
\text { to-noise ratio } \\
\text { - } \\
\text { - EC: } \\
\text { scrept for EC: low resolution } \\
\text { screening }\end{array}$ \\
\hline NMR & 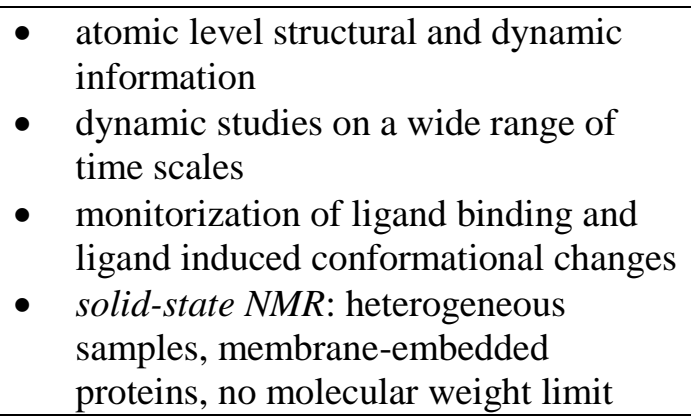 & 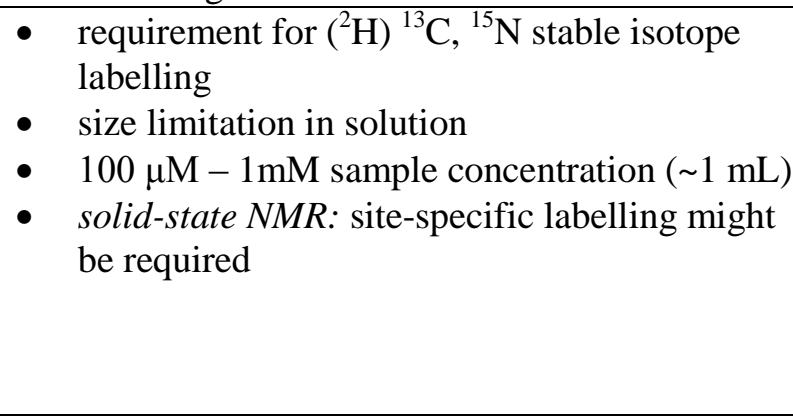 \\
\hline EPR & $\begin{array}{ll}\text { - } & \text { both structural and dynamic } \\
\text { information } \\
\text { - } \\
\text { - } \quad<1.5 \mathrm{~nm} \text { ndistance measurements in } \\
\text { solution } \\
\text { - solution state structure and dynamics } \\
(\mathrm{ns}-\mu \mathrm{s})\end{array}$ & $\begin{array}{l}\text { - } \quad \text { need for paramagnetic label(s) } \\
\text { - } \quad \text { residue level structural/dynamic information } \\
\text { in the frozen state }(\sim 70 \mathrm{~K})\end{array}$ \\
\hline $\begin{array}{l}\text { SAXS } \\
\text { SANS }\end{array}$ & $\begin{array}{l}\text { - information on shape, assembly state, } \\
\text { aggregation, flexibility } \\
\text { - } \quad \text { ideal complementary tool for XRC in } \\
\text { the solution state } \\
\text { - no size limitation }\end{array}$ & $\begin{array}{ll}\text { - } & \text { low resolution } \\
\text { - deuteration may be necessary for SANS }\end{array}$ \\
\hline MS & 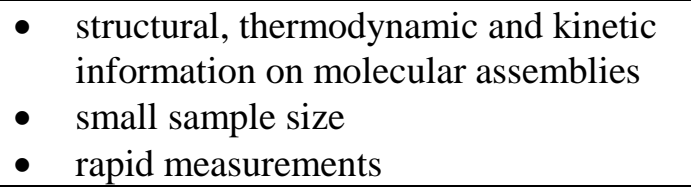 & $\begin{array}{l}\text { - } \text { ionization conditions can be detrimental } \\
\text { - no direct structural information }\end{array}$ \\
\hline
\end{tabular}

Abbreviations - XRC: X-ray crystallization; FS: fluorescence spectroscopy; EM: electron microscopy; EC: electron crystallography; NMR: nuclear magnetic resonance spectroscopy; EPR: electron paramagnetic resonance; SAXS: small-angle X-ray scattering; SANS: small-angle neutron scattering; MS: mass spectroscopy 


\section{Legends to the Figures:}

Fig. 1. The signalling role of structural asymmetry for GPCR dimers. Agonists and/or allosteric agents (A) bind to EC sites on either $R_{1}$ or $R_{2}$ each with different affinities $\left(K_{d}\right)$. The figure shows class C GPCRs with a Venus flytrap EC domain. Agonists close this flytrap (right tilt of the EC domain). In class A receptors lacking this EC domain agonists bind in a cavity close to the top of the TM region. In class B glucagon receptors (not shown) an extending EC region ('stalk') seems to facilitate the TM insertion of peptide agonists (Siu et al., 2013). Ligand binding elicits asymmetric rearrangements of subunit interfaces and conformational changes in the TM helices of the same or other subunit (cis or trans activation, respectively). This leads to differences in down-stream signalling via G proteins, arrestins, and various GPCR-interacting proteins bound to IC sites. Based on Maurice et al., 2011.

Fig. 2. Sensor domains of histidine kinase receptor dimers: correlations of ligand binding, dimer (a)symmetry, and enzyme activity.

TMAO: trimethylamine-N-oxide, Al-2: a furanosyl borate diester. Based on Moore and Hendrickson, 2012. References for the XRC structures of unliganded and liganded sensors.

Fig. 3. Top view of the XRC structure of GLIC, a prokaryotic pLGIC homopentamer cocrystallized with propofol (purple) bound in all five TM cavities in symmetric arrangement. ELIC is a pharmacologically relevant homopentameric pLGIC model: Activation via an asymmetric binding pattern of GABA in nonadjacent EC interfaces (blue arrows) and of a benzodiazepine to an adjacent EC site (red circle). Based on Spurny et al., 2012, by Maksay, 2013. Courtesy of Prof. P. Tang and Trends Pharm. Sci., Elsevier.

Fig. 4. Secondary transporters. A) Left: Extracellular view of the crystal structure of the asymmetric $\mathrm{Glt}_{\mathrm{Ph}}-\mathrm{V} 198 \mathrm{CA} 380 \mathrm{C}_{\mathrm{Hg}}$ trimer (PDB entry: $3 \mathrm{~V} 8 \mathrm{G}$ ) with two protomers in the IFS (light) and one in 
the intermediate iOFS (dark). Right: The iOFS and one IFS protomer viewed within the membrane plane. B) Membrane topology of a single Glt $_{\mathrm{Ph}}$ protomer showing the sequential order of inverted repeat elements. TM segments comprising the scaffold region (TM1-TM6) are blue and green for the two inverted repeats. The C-terminal core region contains two re-entrant helical hairpins (HP1, HP2, pink), and TM7-TM8 (yellow). The trimerisation domain is built from the two V-motifs (TM1, TM2, TM4, TM5), whereas the transport domain contains two arms (TM3, TM6) and the core domain. HP1 and HP2 act as IC and EC gates, respectively. C) Conformational changes in a single protomer upon transition from the IFS (left) to the OFS (right, PDB: 1XFH). The iOFS of $\mathrm{Glt}_{\mathrm{Ph}}-\mathrm{V} 198 \mathrm{CA} 380 \mathrm{C}_{\mathrm{Hg}}$ is shown in the middle. Colour coding as in B). Bound L-aspartate (black) and sodium ions (red) are shown as spheres. D) Cartoon representation of alternating access for substrate and ion symport showing a single protomer. Binding of substrate and co-substrate is coupled to EC gate closure, followed by conformational transition into IFS, and opening of the IC gate. Substrate and ion release into the cytoplasm and closure of the IC gate leave the transporter in an empty IFS. Isomerisation back to the OFS resets the starting state. The EC and IC gates are shown in pink. 


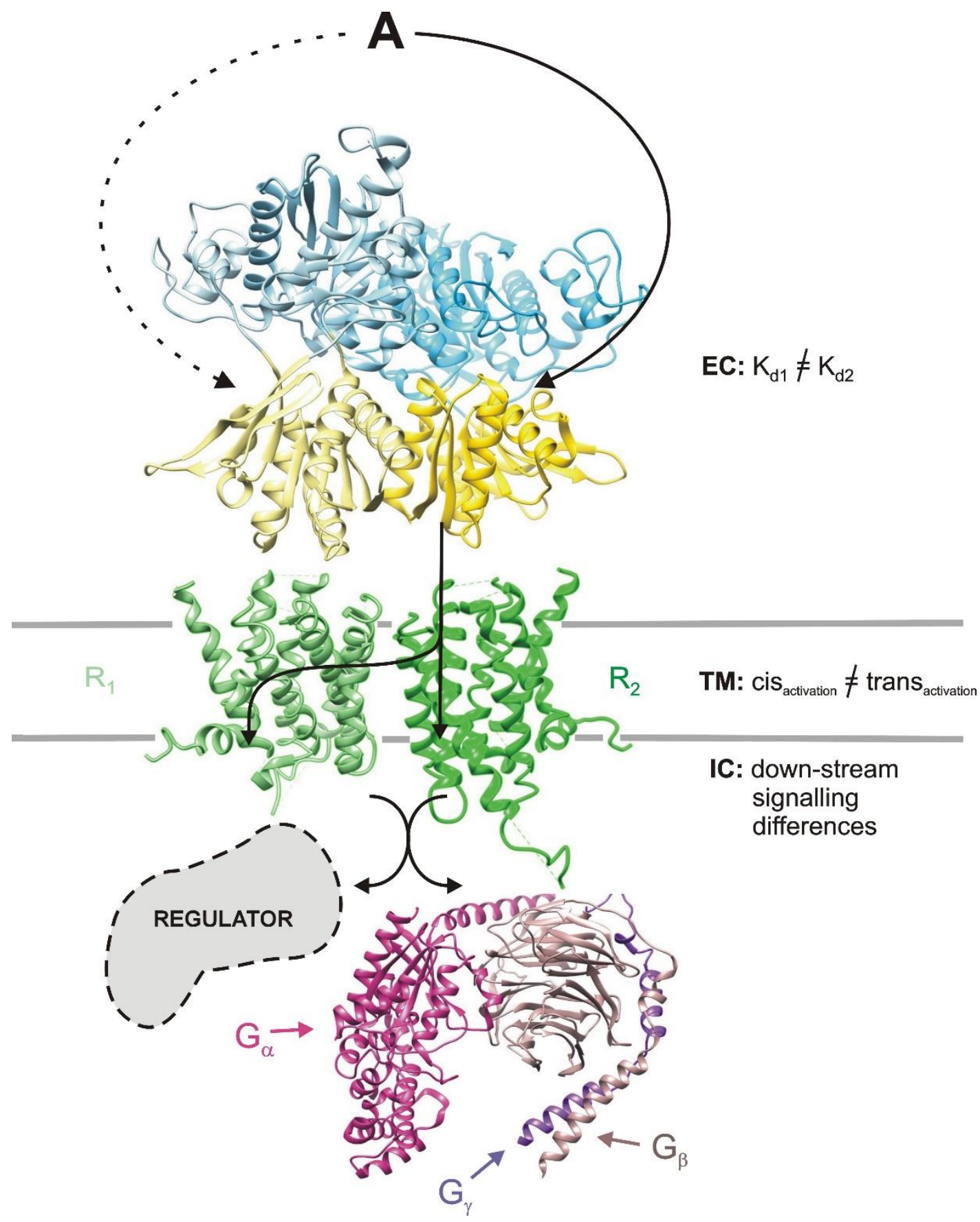

Fig. 1 
SENSOR

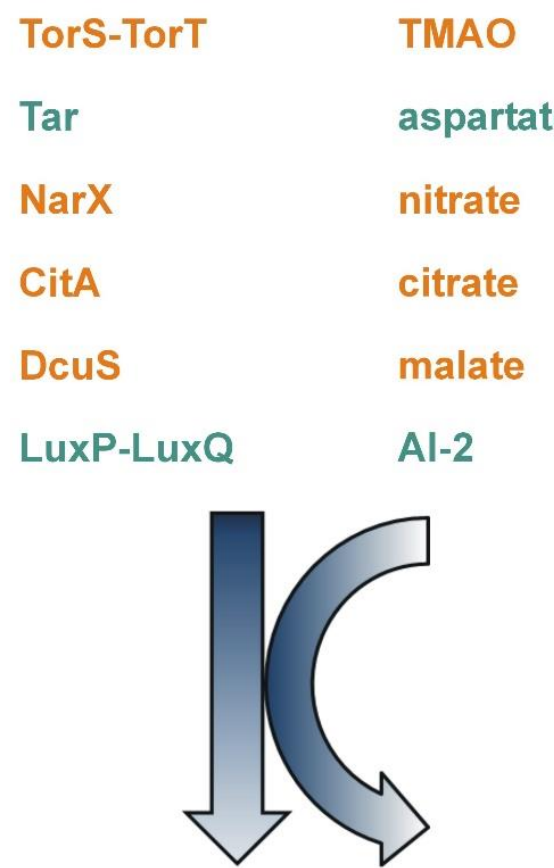

ACTIVITY

phosphatase

kinase

SYMMETRY

asymmetric symmetric

\section{LIGAND}

\section{REFERENCE}

Moore and Hendrickson, 2012

Milburn et al., 1991

Cheung and Hendrickson, 2009

Sevvana et al., 2008

Cheung and Hendrickson, 2008

Neiditch et al., 2006

Fig. 2 


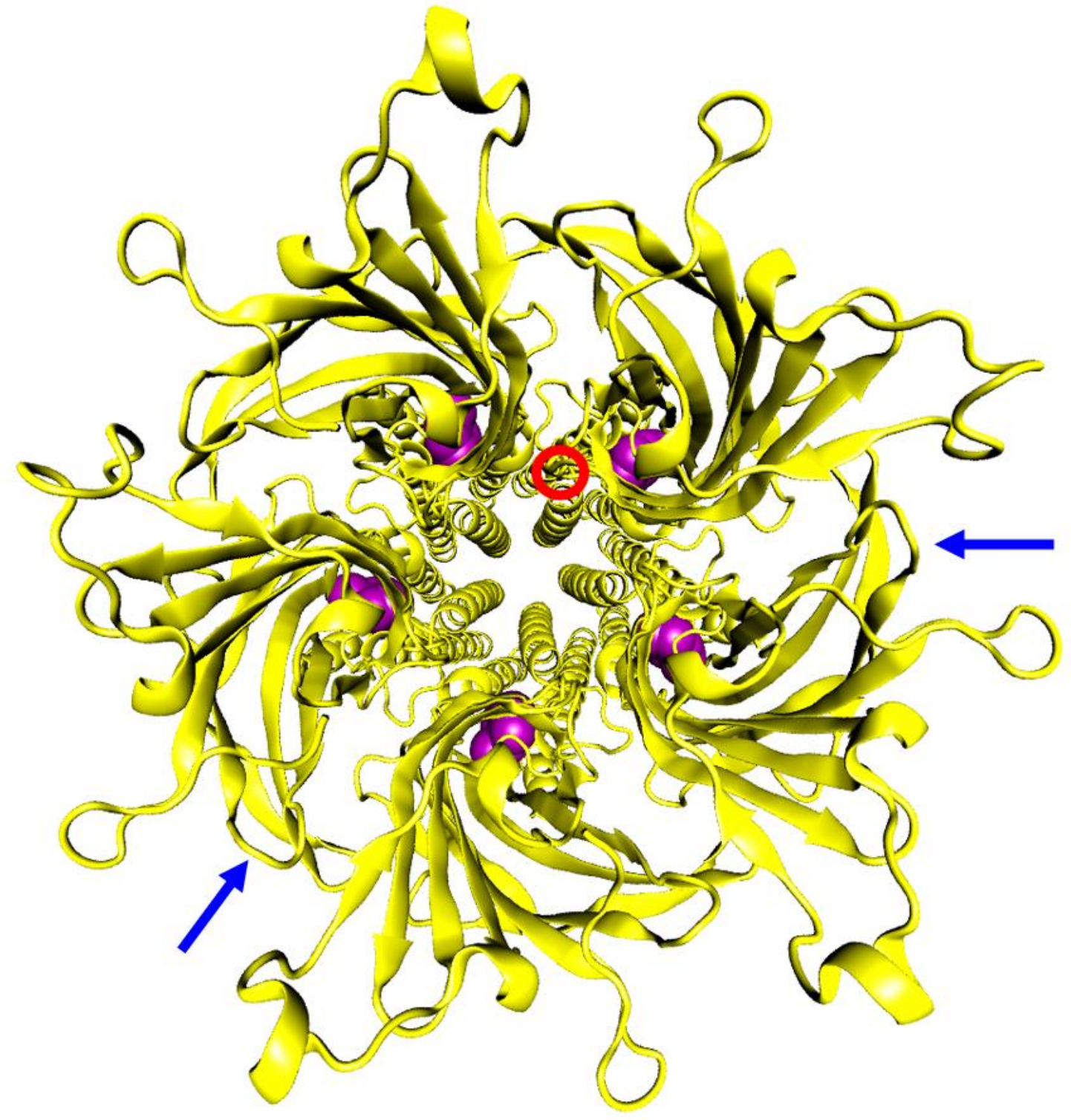

Fig. 3 
A
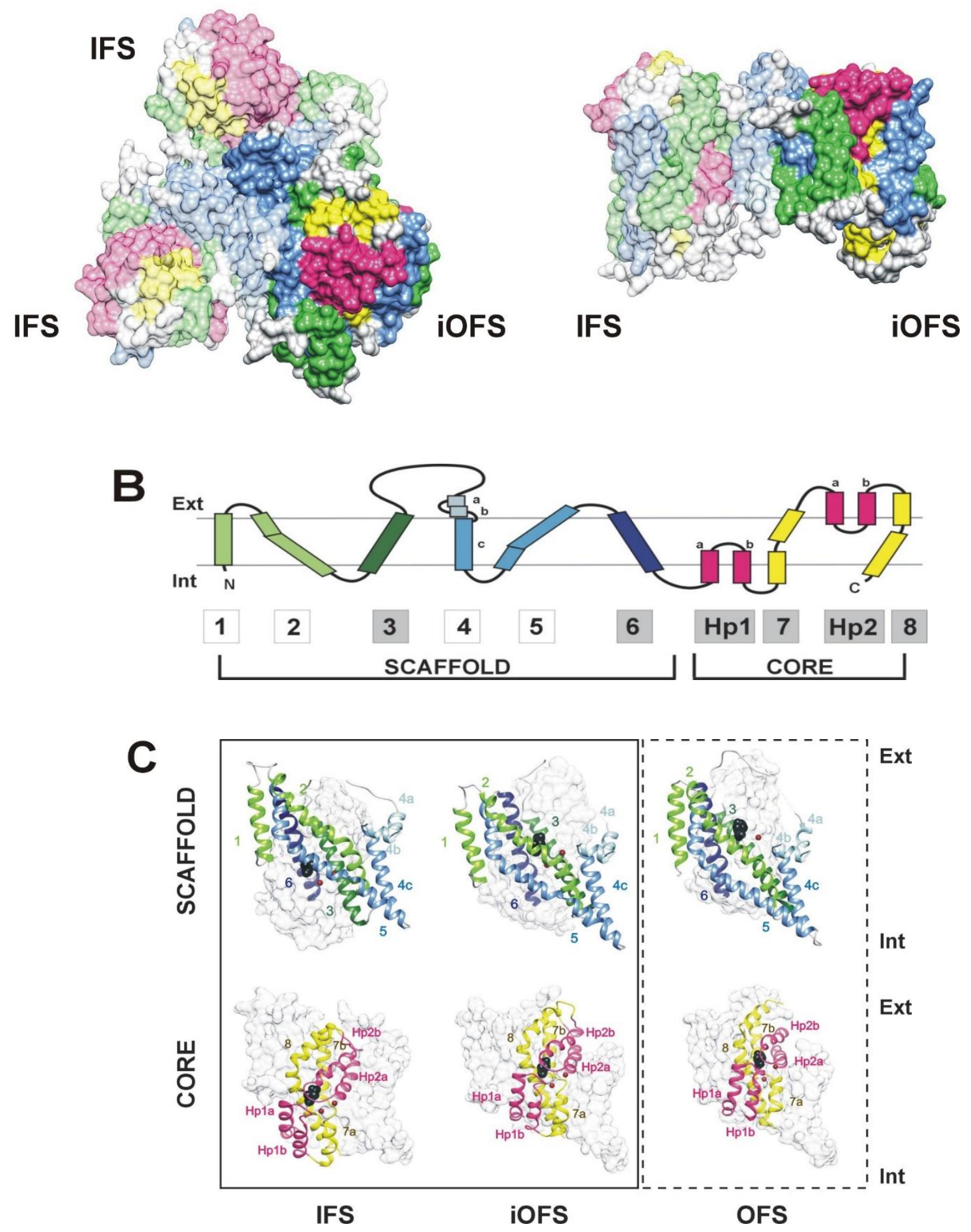


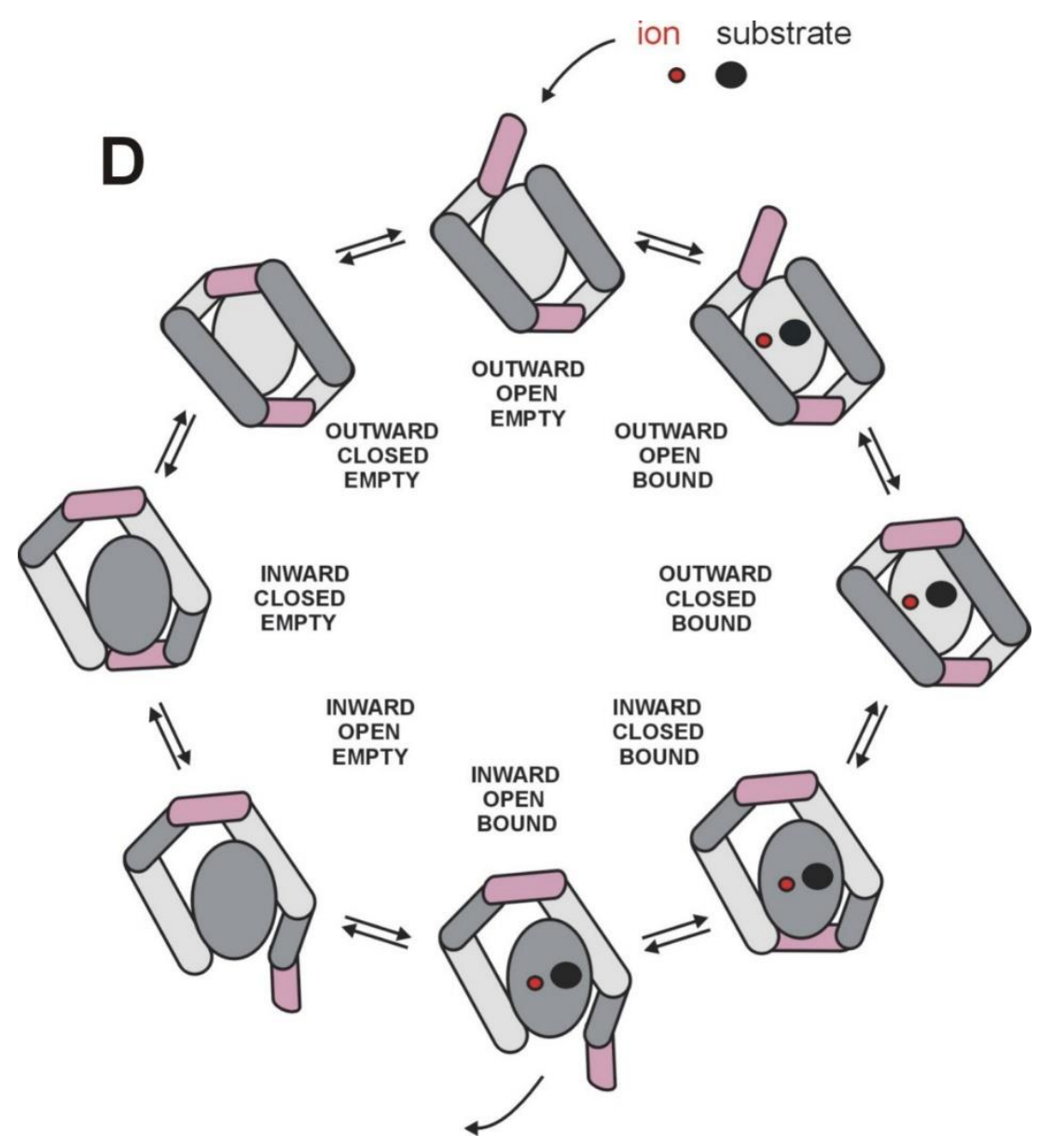

Fig. 4 